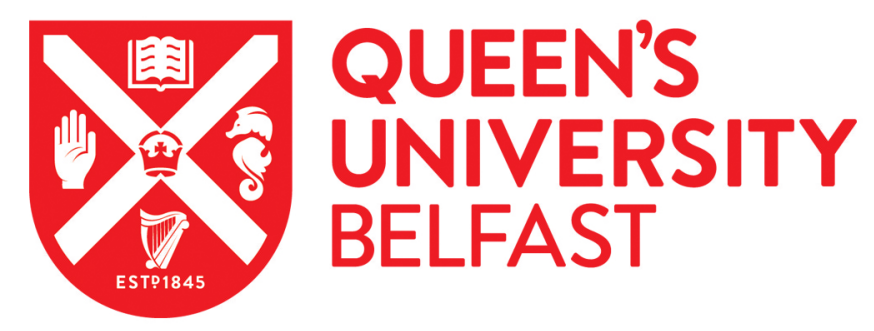

\title{
Numerical investigation of dual-stage high velocity oxy-fuel (HVOF) thermal spray process: A study on nozzle geometrical parameters
}

Jafari, H., Emami, S., \& Mahmoudi, Y. (2017). Numerical investigation of dual-stage high velocity oxy-fuel (HVOF) thermal spray process: A study on nozzle geometrical parameters. Applied Thermal Engineering, 111, 745-758. https://doi.org/10.1016/j.applthermaleng.2016.09.145

Published in:

Applied Thermal Engineering

Document Version:

Peer reviewed version

Queen's University Belfast - Research Portal:

Link to publication record in Queen's University Belfast Research Portal

Publisher rights

(c) Elsevier Ltd 2017. This manuscript version is made available under the CC-BY-NC-ND 4.0 license http://creativecommons.org/licenses/by$\mathrm{nc}-\mathrm{nd} / 4.0 /$ which permits distribution and reproduction for non-commercial purposes, provided the author and source are cited.

\section{General rights}

Copyright for the publications made accessible via the Queen's University Belfast Research Portal is retained by the author(s) and / or other copyright owners and it is a condition of accessing these publications that users recognise and abide by the legal requirements associated with these rights.

Take down policy

The Research Portal is Queen's institutional repository that provides access to Queen's research output. Every effort has been made to ensure that content in the Research Portal does not infringe any person's rights, or applicable UK laws. If you discover content in the Research Portal that you believe breaches copyright or violates any law, please contact openaccess@qub.ac.uk. 


\title{
Numerical investigation of dual-stage high velocity oxy-fuel (HVOF) thermal spray process: a study on nozzle geometrical parameters
}

\author{
Hamed Jafari ${ }^{1}$, Sobhan Emami ${ }^{1 *}$, Yasser Mahmoudi ${ }^{2}$ \\ ${ }^{1}$ Department of Mechanical Engineering, Najafabad Branch, Islamic Azad University, Najafabad, Iran. \\ ${ }^{2}$ School of Mechanical and Aerospace Engineering, Queen's University Belfast, Belfast BT9 5AH, UK. \\ * Correspondence to \\ Tel.: +98 3142292383; Fax: +98 3142291016; Email: sobhan@pmc.iaun.ac.ir.
}

\begin{abstract}
The present study takes the advantage of computational fluid dynamics (CFD) methods to model steady-state, two-dimensional, axisymmetric, turbulent, compressible and combusting flow in a dual-stage high velocity oxy-fuel (HVOF) thermal spray system. The Eulerian method is used to solve the continuum gas phase and the Lagrangian method is utilized for tracking the particles. The effects of particle loads on the continuous gas phase are included in the simulation. Thus, compared to the previous studies, we investigate the influence of coupling between the particle and gas phases in modeling of the dual-stage HVOF process. It is found that decouple modeling of the particle and the continuous phase causes a significant error in velocity of particle at the impact moment, even for low powder particle loading. We further investigate the effects of four geometrical parameters on the behavior of gas phase and consequently the particle phase. Results also show that the turbulent intensity of flow at different sections of the warm spray process is the most important factor determining the radial distribution of nitrogen and temperature in the barrel. It also determines the radial distribution of oxygen in the free jet outside of the barrel. It is further found that reduction of the first nozzle diameter and increasing the length of the divergent section (for a fixed divergent angle) of the convergent-divergent nozzle reduce the particle temperature while these changes do not affect the particle velocity. In other words, changing these geometrical parameters has a desirable effect on the particle temperature without causing an undesirable change on the particle velocity.
\end{abstract}

Keywords: thermal spray, dual-stage high velocity oxy-fuel (HVOF), coupled two-phase model, turbulent mixing, warm spray gun geometry.

\section{Introduction}

Engineering components are usually exposed to destructive environments, and coating is one of the most common and historical ways for protection of these components. Every component based on its mechanical performance and environment properties requires its own coating material and method. From all coating materials, titanium is an excellent coating material for different applications including biomedical implants [1,2], off shore structures [3] and aerospace industry components [4]. The merit of titanium as a coating material nested in its high strength to weight ratio, corrosion resistance, biocompatibility and osseointegrate ability with living organisms [1, 4, 5-8]. Thermal spray techniques like high-velocity oxygen-fuel (HVOF) are common to be used for coating different metals. 
Conventional single-stage HVOF thermal spray systems are typically a high pressure combustion chamber followed by a converging-diverging (C-D) nozzle. Injected particles are accelerated and heated through subsonic and then supersonic combusting gas flow and hit the substrate which is placed at around $300 \mathrm{~mm}$ from nozzle exit [9]. In order to form a layer of high quality coating, proper temperature and velocity at the impact moment need to be obtained [9]. HVOF has found to be one of the most efficient techniques to deposit high performance coatings at moderate cost [10]. However, HVOF system has no powerful control over the gas phase temperature and consequently the particle phase temperature. As it can be seen in Fig. 1, the particle temperature in HVOF system is above $900 \mathrm{~K}$ and it can go over $2000 \mathrm{~K}$. Furthermore, in HVOF system, desirable change in temperature can cause an undesirable change in other characteristics. It is shown by Shamim et al. [11] that a decrease of reactant mass flow rate can cause a tiny desirable reduce in particle temperature but a drastic undesirable decrease in velocity. Moreover, decrease in fuel/oxygen ratio can reduce the temperature, instead produces unburned oxygen and hence increases coating oxide content [11].

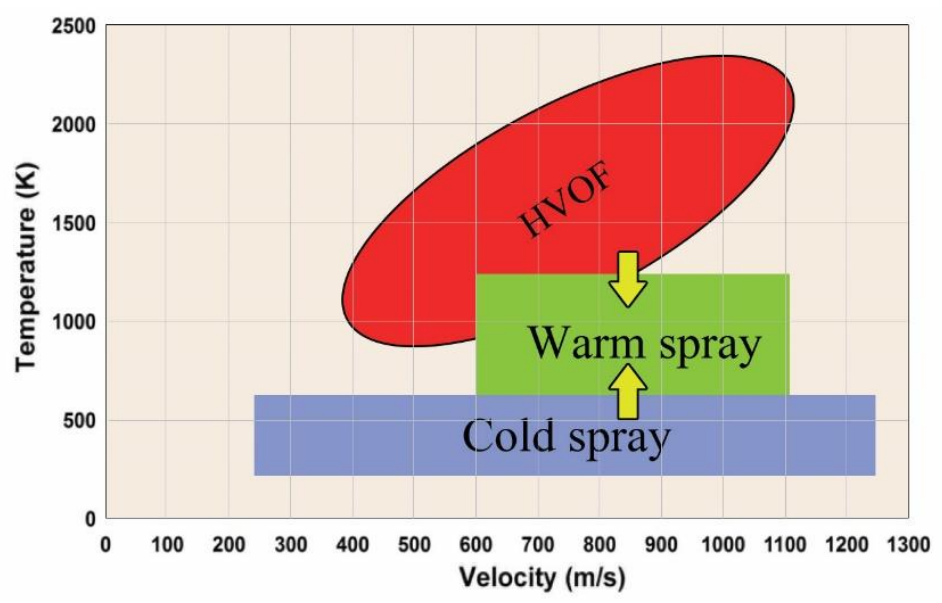

Fig. 1. Comparison of particle velocity and temperature in HVOF, cold spray and warm spray thermal spray processes [9] (published with permission).

Therefore, these limitations make single-stage HVOF thermal spray not a suitable coating method for phase-sensitive and temperature sensitive metals like titanium. Melting point of titanium is very low. It also has strong affinity toward oxygen and reacts with oxygen at relatively lower temperature compared to other materials [12]. Therefore, it is necessary to keep the temperature of titanium low since its oxidation rate increases exponentially when the particle temperature reaches to about $900 \mathrm{~K}$ [13]. Thus, using titanium in single-stage HVOF guns results in very low coating quality with high oxide content. One common titanium coating technique, which can control various detrimental reactions such as oxidation, is cold spray [14, 15]. As it is shown in Fig. 1, particle has low temperature in cold spray, and it hits the substrate while it is in the solid state. This coating system results in low deposition efficiency and high porosities within the coatings [16].

Dual-stage HVOF thermal spray system, which is also called warm spray, is introduced to fill the gap between the cold spray and single-stage HVOF spray processes [9]. Warm spray process inherits particle high momentum from cold spray and high temperature from HVOF spray. Titanium requires both of these characteristics (i.e. high velocity and controlled high temperature) in order to form dense, uniform, low oxide, well adhered and in one word high quality coatings. 
Warm spray was first patented by Browning [17] and then developed by many researchers [1821]. The principles of warm spray are similar to HVOF process. As can be seen in Fig. 2, a converging nozzle followed by a mixing chamber is placed between combustion chamber and CD nozzle. In the mixing chamber different mass flow rates of nitrogen are added as coolant in order to dilute the hot gases. This can be known as the powerful temperature regulator in warm spray technique. Warm spray gun also has a barrel which joins to the C-D nozzle, and particles are introduced to the flow at the barrel entrance. Based on a study by Kuroda et al. [9], warm spray can maintain particle temperature in the range of 850-1400 $\mathrm{K}$ and particle velocity in the range of $620-800 \mathrm{~m} / \mathrm{s}$. In such a range of velocity, the particle temperature in HVAF (high velocity air fuel) gun is between 1100-1300 K. In other words, Kuroda et al. [9] showed that the warm spray provides particle temperature three times wider than HVAF while maintaining the velocity comparable with it.
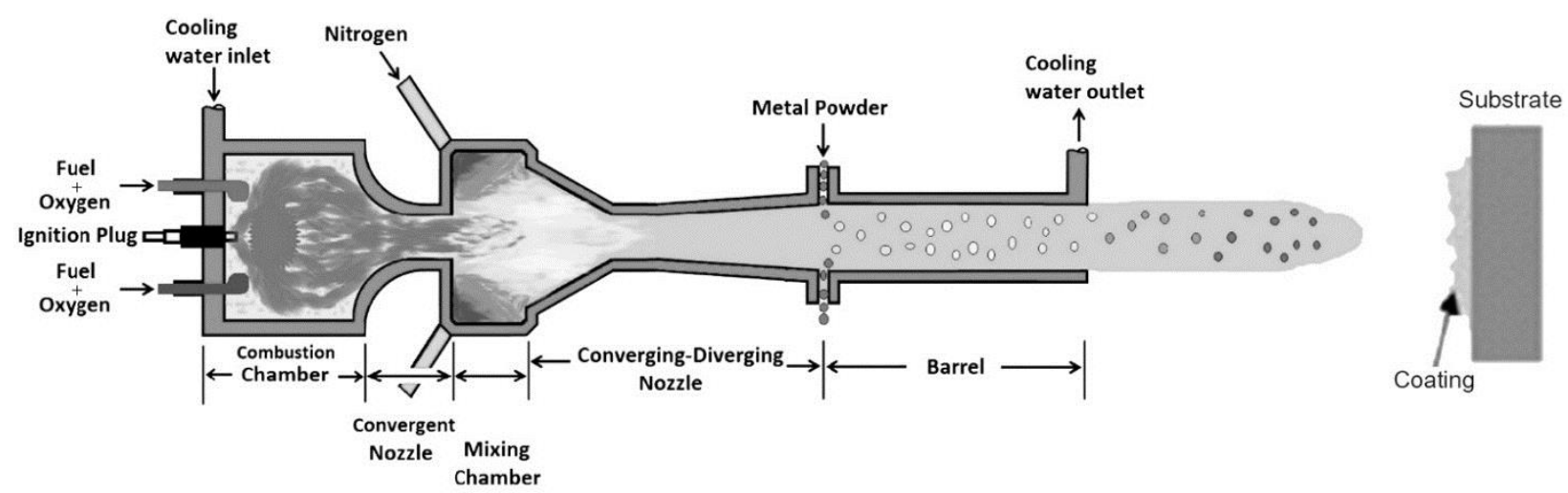

The processes in the thermal spray guns are very complex and involve multi-phase turbulent flow, chemical reaction, heat transfer and supersonic/subsonic flow transition [22]. Moreover, the influence of processing conditions on particle characteristics and coating quality is highly nonlinear and might not be thoroughly revealed by experimental studies [23]. Hence, numerical techniques are effective tools and can provide an insight into the underlying momentum and heat transfer mechanisms [24, 25]. This further helps to improve the efficiency of HVOF and warm spray coatings by optimizing all of the effective design parameters such as C-D nozzle geometry, fuel/oxygen ratio, particle size and so on [16, 23-31].

While many computational fluid dynamics (CFD) simulations have been done to investigate single-stage HVOF process, researches on the dual-stage HVOF are scarce. Tabbara et al. [3] were pioneered in performing numerical study on the modified HVOF gun. They studied the impact of nitrogen flow rate, nitrogen radial concentration in the barrel and particle trajectory on the particle temperature and velocity. It was concluded that increasing the rate of nitrogen leads to an increase of pressure in the upstream of C-D nozzle, and this intensifies the under-expansion of flow at nozzle outlet. They also found that in the near wall region, where the flow has lower temperature and lower axial velocity, the concentration of the nitrogen is more than central region. Moreover, it was deduced that smaller particles are more likely to get away from the centerline and move to the near wall region. Moreover, the importance of mixing between hot combustion gases and cold nitrogen on the performance of warm spray was emphasized in their paper [3]. Khan and Shamim [16] studied the effects of reactant and coolant mass flow rate and fuel/oxygen ratio on gas and 
particle phases in a warm spray process. They [16] concluded that increasing the reactant mass flow rate increases the particle temperature and velocity. It was further concluded that the highest gas phase temperature occurs at stoichiometric mixture point while particle temperature increases as the fuel/oxygen ratio increases [16]. More coolant flow rate reduces particle temperature and increases the particle velocity only outside of the barrel [16]. Khan and Shamim [30] also investigated the influence of some geometrical parameters in a dual-stage HVOF system and reported that an increase in the combustion chamber diameter or length leads to a decrease in temperature and velocity of particles. They [30] also reported that increasing the length of mixing chamber leads to an increase in the gas phase residence time in the mixing chamber and results in better mixing between the hot gases and nitrogen. It causes a significant decrease in the particle temperature. Increase in the diameter of C-D nozzle exit, however, reduces the particle velocity and increases its temperature [30].

The above literature review shows that mixing between hot gases and cold nitrogen is the most sensitive factor and has significant effects on the gas dynamic and thermal behavior of flow in the warm spray and consequently on the particle conditions (i.e. temperature and velocity). Therefore, the aim of the present work is studying the nozzle geometry which mostly controls the mixing of hot gases and nitrogen. The paper also visualizes the details of the flow properties in the converging nozzle and C-D nozzle of a dual-stage HVOF. This provides an overview of the sensitivity of the problem upon the geometry of the system. Hence, it highlights the regions in the parametric space in which the choice of the nozzle geometry leads to an optimum design of a warm spray. The current paper investigates the influence of four effective geometric parameters of dualstage HVOF gun. These parameters are (i) converging nozzle throat diameter, (ii) C-D nozzle throat diameter, (iii) simultaneous changing of throat diameter of converging nozzle and C-D nozzle and (iv) length of the divergent section of C-D nozzle. In addition, the previous numerical studies considered low particle loading and assumed that the particle phase is decoupled from the gas phase. Thus, another aim of the present work is to investigate the influence of coupling between the particle phase and the gas phases in modeling of a dual-stage HVOF system. The problem includes steady-state, axisymmetric flow calculations for turbulent, fully compressible, high-speed and chemically combusting gas flow. The paper is organized as follows. In section 2 we provide the model development and the governing equations. Turbulence and combustion models and the dynamics of the gas and particle phases are introduced in this section. In this section we further give details on the numerical method, computational domain and boundary conditions used to solve the governing equations. Section 3 presents the grid study and verification of the results against previous studies. In section 4 the effect of coupling solution on the particle dynamic is examined. In section 5 the results of the numerical modeling are presented and discussed. In this section the effect of geometrical parameters of the nozzle are studied in detail. Finally section 6 concludes the paper.

\section{Model development and mathematical formulation}

In the current study, the Eulerian formulation is used to solve the flow field and Lagrangian particle tracking method is utilized to provide particle flow characteristics. The particle phase is coupled with the gas phase, and the impact of particle loads on the gas phase is considered. The gas phase problem contains mass, momentum and energy conservation equations along with turbulence and equilibrium chemistry. The Eulerian method utilizes ideal gas assumption to deal with high speed, 
compressible and Newtonian flow. Results from gas phase provides Lagrangian scheme with data to determine particle velocity, temperature and location. Since warm spray gun is completely axisymmetric, a two-dimensional domain is appropriate for computations.

To incorporate the effect of different physical phenomena involve in the problem, we used existing models in the literature. This is mainly due to the complexity of the multi-scale problem involving, compressible turbulent reactive phenomena with heat transfer, and modeling of C-D nozzle in a complicated geometry. Interaction between the continuum gas phase by solving Euler equation and tracking particle phase using Lagrangian method, adds more complexity to the problem. Therefore, we tried to utilize previous validated models to develop a validated modeling tool. This further allows us to have a quick model for the purpose of parametric and geometric studies that is the objective of the present work.

\subsection{Gas phase dynamics}

Viscous, compressible and turbulent flow in a warm spray gun is governed by the compressible reactive Navier-Stokes equations. This consists of balance equations for mass, momentum, energy and species. The ideal gas equation of state couples the pressure and density. The governing equations solved in this study are obtained by Favre (mass-weighted) averaging of transport equations. Therefore, the steady state continuity and momentum equations are written as:

$$
\begin{aligned}
& \frac{\partial\left(\bar{\rho} \widetilde{u}_{j}\right)}{\partial x_{j}}=0, \\
& \frac{\partial\left(\bar{\rho} \widetilde{u}_{j} \widetilde{u}_{i}\right)}{\partial x_{j}}=-\frac{\partial \bar{p}}{\partial x_{i}}+\frac{\partial}{\partial x_{j}}\left(\left(\bar{\tau}_{i j}\right)_{e f f}\right)+S_{m o m, p}, \\
& \left(\bar{\tau}_{i j}\right)_{e f f}=\mu_{e f f}\left(\frac{\partial \widetilde{u}_{i}}{\partial x_{j}}+\frac{\partial \widetilde{u}_{j}}{\partial x_{i}}\right)-\frac{2}{3} \mu_{e f f} \frac{\partial \widetilde{u}_{l}}{\partial x_{l}} \delta_{i j},
\end{aligned}
$$

where $\rho$ is the density of gas, $u_{j}$ is the $j^{\text {th }}$ component of the gas field velocity, $p$ is the static pressure, and $\mu_{\text {eff }}$ is the effective viscosity that is considered as the summation of the molecular viscosity, $\mu$, and turbulent eddy viscosity, $\mu_{t}$. Eddy viscosity is resulted from Reynolds stress terms and represents the effect of diffusing momentum. $\left(\bar{\tau}_{i j}\right)_{\text {eff }}$ and $\delta_{i j}$ are the mean deviatoric stress tensor and the Kronecker symbol respectively. The superscripts $(\sim)$ and $(-)$ denote a massweighted averaged quantity and a Reynolds averaged quantity.

In order to simulate two-way coupling, we need to consider the effect of particles on the momentum and energy equations of the continuous phase. Therefore, two terms appear as momentum and energy sinks in the continuous phase equations. For momentum equation (Eq. (2)) the source term $S_{m o m, p}$ is calculated as:

$$
S_{m o m, p}=-\frac{18}{24} \frac{C_{D} \rho_{g}}{d_{p}}\left(\overrightarrow{U_{g}}-\overrightarrow{U_{P}}\right)\left|\overrightarrow{U_{g}}-\overrightarrow{U_{P}}\right|,
$$

where $\rho_{g}$ and $d_{p}$ are the density of gas and diameter of particle, respectively. $C_{D}, U_{g}$ and $U_{P}$ are drag coefficient, gas phase velocity and particle phase velocity, respectively

The balance equations for energy and species are: 


$$
\begin{aligned}
& \frac{\partial}{\partial x_{i}}\left[\tilde{u}_{i}\left(\bar{\rho} \tilde{h}_{t}+\bar{p}\right)\right]=\frac{\partial}{\partial x_{j}}\left[\left(\lambda+\frac{c_{p} \mu_{t}}{P r_{t}}\right) \frac{\partial \tilde{T}}{\partial x_{j}}+\tilde{u}_{i}\left(\left(\bar{\tau}_{i j}\right)_{e f f}\right)-\sum_{k=1}^{N_{s}} \bar{J}_{k} \tilde{h}_{k}\right]+S_{\text {heat }, p}, \\
& \frac{\partial}{\partial x_{j}}\left(\bar{\rho} \tilde{Y}_{k} \tilde{u}_{j}\right)=-\frac{\partial}{\partial x_{j}}\left[\bar{J}_{k}\right]+\overline{\dot{\omega}}_{k} ; k=1, \cdots, \mathrm{N}_{s}-1,
\end{aligned}
$$

where $T$ is the temperature, $h_{t}$ is the total enthalpy obtained as $h_{t}=h+u_{i} u_{i} / 2, \lambda$ is the thermal conductivity, $Y_{k}$ is mass fraction of the species $k$ and $\dot{\omega}_{k}$ is the mass reaction rate of species per unit volume. $\bar{J}_{k}$ is the diffusion flux of a species $k$ consists of molecular diffusion and effective diffusion due to turbulence. $P r_{t}$ is the turbulent Prandtl number that is estimated using Eq. (7) based on the RNG theory [32]:

$\left|\frac{\alpha-1.3929}{\alpha_{0}-1.3929}\right|^{0.6321}\left|\frac{\alpha+2.3929}{\alpha_{0}+2.3929}\right|^{0.3679}=\frac{\mu}{\mu_{t}}$,

where $\mu$ is the molecular viscosity, $\mu_{t}$ is the turbulent eddy viscosity, $\alpha_{0}=1$, and $\alpha=1 / P r_{t}$. The results that obtained from Eq. (7) for $P r_{t}$ is in close agreement with experimental data in a variety of flows [32]. This equation has also been used to investigate turbulent reactive flow in the single HVOF and dual stage HVOF (e.g. [16, 22, 26, 28, 30, 31, 43]). For single HVOF, turbulent properties of the flow predicted using Eq. (7), were in good agreement with experimental data [16]. In high Reynolds number, fully developed turbulence flow where $\mu / \mu_{t}$ tends to zero, $\alpha$ becomes 1.3929 and the turbulent Prandtl number is $\operatorname{Pr}_{t}=0.7179$.

In Eq. (5) $S_{\text {heat }, p}$ is the energy sink in the energy equation of the continuous phase and is calculated by:

$S_{\text {heat }, p}=-\rho_{P} C_{P} \frac{d T_{P}}{d t}$,

where $\rho_{P}, C_{p}$ and $T_{p}$ is density, specific heat at constant pressure and temperature of the particle, respectively.

\subsubsection{Turbulence model}

In this study the re-normalization group (RNG) $k-\varepsilon$ model along with the non-equilibrium wall function treatment is used to predict the turbulent eddy viscosity. Since the nature of the flow in warm spray gun includes complex shear flows [30] with rapid strain and large pressure gradient, RNG $k-\varepsilon$ is a stronger model in comparison with standard $k-\varepsilon$ in order to predict turbulent core of the flow field [33]. This model provides good results for the core flow when the wall y plus is between 30 and 300 [33], which is satisfied in the current simulation. Nonetheless, it cannot solve the flow in the boundary layer accurately [33]. However, RNG $k-\varepsilon$ is accurate enough to investigate the overall impacts of the geometrical parameters on the flow and particle field. In the RNG $k-\varepsilon$ turbulence model the turbulent kinetic energy, $k$, and the rate of turbulent kinetic energy dissipation, $\varepsilon$, are expressed as follows:

$$
\begin{aligned}
& \frac{\partial\left(\bar{\rho} \widetilde{u}_{j} k\right)}{\partial x_{j}}=\frac{\partial}{\partial x_{j}}\left[\alpha_{k}\left(\mu+\mu_{t}\right) \frac{\partial k}{\partial x_{j}}\right]+G_{k}-\bar{\rho} \varepsilon-Y_{M}, \\
& \frac{\partial\left(\bar{\rho} \widetilde{u}_{j} \varepsilon\right)}{\partial x_{j}}=\frac{\partial}{\partial x_{j}}\left[\alpha_{\varepsilon}\left(\mu+\mu_{t}\right) \frac{\partial \varepsilon}{\partial x_{j}}\right]+\frac{\varepsilon}{k}\left(C_{1 \varepsilon} G_{k}-\bar{\rho} C_{2 \varepsilon} \varepsilon\right)-R_{\varepsilon} .
\end{aligned}
$$


The constant values of the model in Eqs. (9) and (10) are $C_{1}=1.42, C_{2}=1.68$ and $C_{\mu}=0.084$. $\alpha_{k}$ and $\alpha_{\varepsilon}$ are the inverse effective Prandtl numbers for $k$ and $\varepsilon$. The production rate of turbulent kinetic energy, $G_{k}$, is written as:

$$
G_{k}=\mu_{t}\left(\frac{\partial \widetilde{u}_{i}}{\partial x_{j}}+\frac{\partial \widetilde{u}_{j}}{\partial x_{i}}\right) \frac{\partial \widetilde{u}_{i}}{\partial x_{j}}-\frac{2}{3}\left(\bar{\rho} k+\mu_{t} \frac{\partial \widetilde{u}_{l}}{\partial x_{l}}\right) \frac{\partial \widetilde{u}_{k}}{\partial x_{k}},
$$

where the turbulent eddy viscosity defined as $\mu_{t}=\bar{\rho} C_{\mu} k^{2} / \varepsilon$.

\subsubsection{Combustion model}

The eddy dissipation model (EDM) developed by Magnussen and Hjertager [34] is the most common combustion model which is utilized in simulation of HVOF and warm spray guns (e.g. $[16,23,24,28,30,35,36])$. The EDM is based on the early eddy break-up combustion model (EBU) which was introduced by Spalding for the first time [37]. In these models, it is assumed that the reaction rate does not depend on chemical characteristics. As a consequence, the combustion rate is mostly controlled by the turbulent movements of the flow. In other words, turbulent flow breaks down eddies with fuel and oxidizer contents, and this process facilitates mixing. In the next step, the reactions are completed at the mixing moment. Therefore, these models are called infinite rate chemistry model or "mixed-is-burnt". Thus, these models are only suitable for problems with high Reynolds and Damkohler numbers (i.e. $R e\rangle\rangle 1$ and $D a\rangle\rangle 1$ ) where reaction time scale is much smaller than mixing time scale (which is estimated by $k / \varepsilon$ ) [38].

In the premixed combustion which happens in the problem of warm spray both fuel and oxygen exist in every single eddy and the minimum dissipation rate of fuel-oxidizer and products will appoint the reaction rate. In EDM, average concentration of species and the turbulent intensity in the flow are the only parameters which determine the reaction rate. Therefore, the volumetric fuel consumption rate is given by:

$$
\overline{\dot{\omega}}=-\bar{\rho} A\left(\frac{\varepsilon}{k}\right) \min \left(\tilde{Y}_{F}, \frac{\tilde{Y}_{O}}{S_{O}}, \frac{B \tilde{Y}_{P}}{1+S_{O}}\right),
$$

where $S_{O}=n_{O} M_{O} / n_{F} M_{F} . A$ and $B$ are constants taken as 4 and 0.5 , respectively [38].

The Eddy Dissipation Model over-predicts the reaction rate in highly strained regions where $\varepsilon / k$ ratio is high [38], and this can cause artificial flame to be observed. Moreover, for regions with similar species concentration and turbulence level but different temperatures, this model predicts similar reaction rate. To overcome these shortcomings, new finite rate chemistry combustion models, like eddy dissipation concept (EDC) model [39] and partially stirred reactor (PaSR) model [40] which consider the effects of chemical kinetics, are developed. It is unlikely that the weaknesses of EDM in comparison with the finite rate chemistry models mainly affect the major variables in the flow field and especially particle field. Nonetheless, the absence of a numerical investigation with detailed chemical kinetics in the HVOF system is still conspicuous, and it can be a topic for future researches.

Since the effect of chemical kinetics is ignored by EDM, the dissociation of major species should be considered in order to avoid the over-prediction of temperature. When combustion occurs, the 
gauge pressure and temperature roughly reach to 3.5 bars and $2800 \mathrm{~K}$ in the base case (the geometry of the base case is introduced in Fig. 3). In such conditions using an instantaneous equilibrium model leads to the following chemical equation:

$\mathrm{C}_{3} \mathrm{H}_{6}+4.307 \mathrm{O}_{2} \rightarrow 1.903 \mathrm{CO}+1.097 \mathrm{CO}_{2}+0.382 \mathrm{H}+0.432 \mathrm{H}_{2}+$ $2.004 \mathrm{H} 2 \mathrm{O}+0.388 \mathrm{O}+0.745 \mathrm{OH}+0.692 \mathrm{O}_{2}$.

The stoichiometric coefficient of each species depends on the combustion chamber pressure and is not known a priori. Li and Christofides [28] used a trial and error method based on a onedimensional (1-D) model along with a chemical equilibrium program (by Gordon and McBride [41]) to calculate the combustion pressure. They [28] showed that for different operating conditions leading to combustion pressures between 3 and 4.8 bars, the difference between calculated pressure from the above mentioned procedure and the experimental data is less than $6 \%$. In this work we used the data presented by Li and Christofides [28] for the chamber pressure.

\subsection{Particle phase dynamics}

The discrete phase model (DPM) takes the advantage of Lagrangian method to determine the particle motion and temperature using data coming from the gas phase momentum and heat transfer equations. It is assumed in previous studies [3, 11, 16, 27, 30, 42] that since the particle loading in the spray process is very low, the effect of particle dynamics on the continuous phase is minimal. Therefore, the particle phase can be decoupled from the gas phase. However, based on what will be discussed in section 4 , decoupling the particle and the continuous phase will cause a remarkable error in prediction of the particle velocity at the impact moment.

It is also assumed that the particles do not affect each other. The particle is considered to be in a spherical shape and their motion is simulated by following equation [33]:

$$
m_{P} \frac{d \overrightarrow{V_{P}}}{d t}=\frac{1}{8} \rho_{g} A_{P} C_{D}\left(\overrightarrow{U_{g}}-\overrightarrow{U_{P}}\right)\left|\overrightarrow{U_{g}}-\overrightarrow{U_{P}}\right|+\vec{F},
$$

where $C_{D}, U_{g}$ and $U_{P}$ are drag coefficient, gas phase velocity and particle phase velocity, respectively. Also $A_{p}$ is the surface area of the particle.

While the roughness and orientation of particle surface are important, the particle Reynolds number $\left(R e_{p}\right)$ is the dominant parameter on the drag coefficient [10]. Thus, the following equations define particle drag coefficient and Reynolds number respectively [33].

$$
\begin{aligned}
C_{D} & =\left\{\begin{array}{c}
\frac{24\left(1+0.15 R e_{P}^{0.687}\right)}{R e_{P}}, R e_{P} \leq 10^{3} \\
0.44, R e_{P}>10^{3}
\end{array}\right\} . \\
R e_{P} & =\rho_{g} \frac{\left|\overrightarrow{U_{g}}-\overrightarrow{U_{P}}\right|}{\mu_{g}} d_{P} .
\end{aligned}
$$

Since the particle Biot number is less than 0.1 [43] the particles internal resistance is ignored and the temperature gradient inside the particle is assumed to be zero. For the base case, we studied the effect of radiation by using the Discrete Ordinate (DO) radiation model. The results predicted for the radiative model are similar to the non-radiative model. Therefore, the effect of radiation is 
ignored for the rest of the cases studied in this paper. Thus, the heat transfer equation between a single particle and continues gas phase is described as:

$$
m_{P} C_{P} \frac{d T_{P}}{d t}=A_{P} h_{c}\left(T_{g}-T_{P}\right)
$$

278

279

280

281

282

283

284

285

286

287

288

289

290

291

292

293

294

295

296

297

where $h_{c}$ is the convection coefficient obtained as $h_{c}=N u \lambda_{g} / d_{P} . N u$ is the Nusselt number defined by Ranz and Marshall correlation [44] as $N u=2.0+0.6 \operatorname{Pr}^{0.33} \operatorname{Re}_{d}^{0.5}$ and $\lambda_{g}$ is the thermal conductivity of the gas phase. $P r$ also is laminar Prandtl number of the continuous phase defined as $c_{p} \mu / \lambda_{g}$.

\subsection{Numerical method}

We utilized the CFD commercial code ANSYS Fluent 16.1 to solve the governing equations. The solver performs under 2-D, axisymmetric, double precision, steady-state and pressure based conditions. The pressure and density are connected using the ideal gas state equation. SemiImplicit Method for Pressure Linked Equations (SIMPLE) algorithm [45] is employed to treat pressure-velocity coupling. SIMPLE algorithm is commonly used in modeling high speed combusting flow in HVOF guns [16, 26, 30, 35, 36]. Since the radial distribution of nitrogen, oxygen and temperature is studied in this paper, the second order upwind discretization approach is utilized for all equations in order to avoid numerical diffusion.

\subsection{Computational domain and boundary conditions}

The schematic diagram and the boundary conditions of a warm spray gun are shown in Fig. 3. The computational domain includes combustion chamber, converging nozzle, mixing chamber, C-D nozzle, barrel and finally atmosphere (where the substrate is located). A, B and C indicate inlets for fuel-oxygen, nitrogen and particle, respectively.

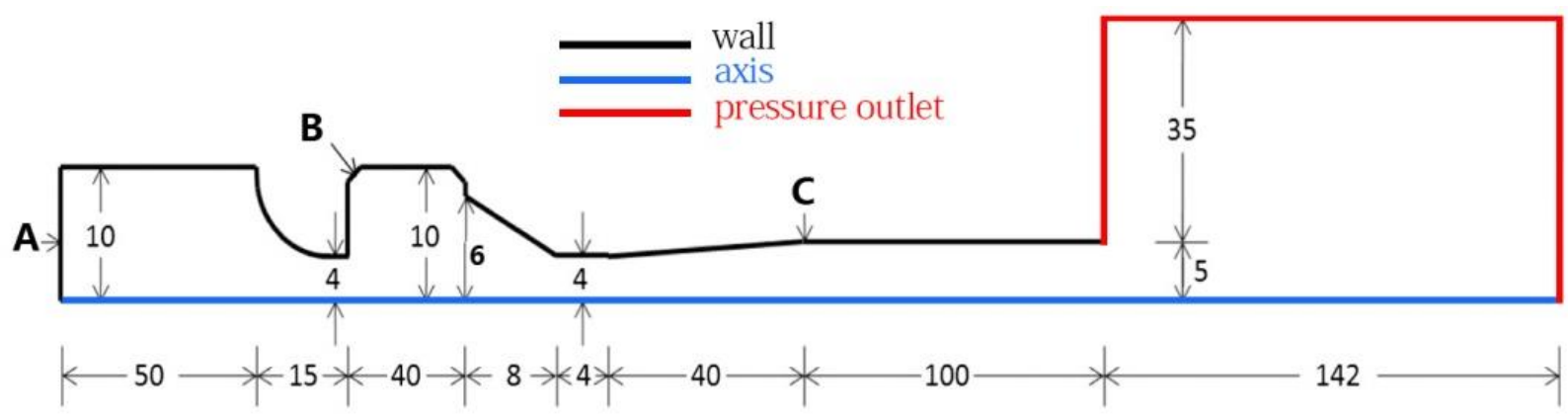

Fig. 3. Schematic diagram and boundary conditions of a typical warm spray gun. Dimensions are in mm for the base case.

The main objective in the present work is to examine the effect of the nozzle geometry (i.e. converging nozzle and C-D nozzle) on the gas flow and particle behavior in the warm spray. To do this, we consider the change of four effective geometric parameters. These are (i) changing throat diameter of the converging nozzle, (ii) changing the throat diameter of the C-D nozzle, (iii) simultaneous changing of the throat diameter for both converging and C-D nozzles and (iv) length of the C-D nozzle divergent section. This generates 13 geometrical cases which are analyzed numerically in this paper. Table 1 presents the variable dimensions for these 13 cases. Table 2 also presents the working conditions of warm spray. All wall temperatures are fixed at $350 \mathrm{~K}$, and the 
entrance temperature of fuel-oxygen, nitrogen and particle is assumed to be $300 \mathrm{~K}$ [30]. The ambient pressure is also fixed at $1 \mathrm{~atm}$. The particle diameter is $15 \mu \mathrm{m}$ and other particle properties are taken from Ref. [30].

Table 1. Description of 13 studied cases. The inlet diameter and the divergent angle of the 2nd nozzle are fixed at $12 \mathrm{~mm}$ and $1.47^{\circ}$, respectively.

\begin{tabular}{|r|c|c|c|}
\hline Base case & $\begin{array}{c}1^{\text {st }} \text { nozzle } \\
\text { throat } \\
\text { diameter }\end{array}$ & $\begin{array}{c}2^{\text {nd }} \text { nozzle } \\
\text { throat } \\
\text { diameter }\end{array}$ & $\begin{array}{c}\text { length of the } \\
2^{\text {nd }} \text { nozzle } \\
\text { divergent } \\
\text { portion }\end{array}$ \\
\hline \begin{tabular}{r|c|c|} 
Case 1 \\
$1^{\text {st }}$ Group Case 2 \\
Case 3
\end{tabular} & $\begin{array}{l}6 \mathrm{~mm} \\
7 \mathrm{~mm}\end{array}$ & $8 \mathrm{~mm}$ & $40 \mathrm{~mm}$ \\
\hline $\begin{array}{r}\text { Case 4 } \\
\text { Case 5 }\end{array}$ & $8 \mathrm{~mm}$ & $6 \mathrm{~mm}$ & $40 \mathrm{~mm}$ \\
Case 6 & & $7 \mathrm{~mm}$ & $40 \mathrm{~mm}$ \\
\hline Case 7 & $6 \mathrm{~mm}$ & $6 \mathrm{~mm}$ & \\
$3^{\text {rd }}$ Group Case 8 & $7 \mathrm{~mm}$ & $7 \mathrm{~mm}$ & $40 \mathrm{~mm}$ \\
Case 9 & $9 \mathrm{~mm}$ & $9 \mathrm{~mm}$ & \\
\hline Case 10 & & & $30 \mathrm{~mm}$ \\
$4^{\text {th }}$ Group Case 11 & $8 \mathrm{~mm}$ & $8 \mathrm{~mm}$ & $35 \mathrm{~mm}$ \\
Case 12 & & & $45 \mathrm{~mm}$ \\
Case 13 & & & $50 \mathrm{~mm}$ \\
\hline
\end{tabular}

Table 2.Operating conditions.

\begin{tabular}{|c|c|}
\hline parameter & value \\
\hline Fuel + Oxygen mass flow rate & $0.008740 \mathrm{~kg} / \mathrm{s}$ \\
Nitrogen mass flow rate & $0.008604 \mathrm{~kg} / \mathrm{s}$ \\
Particle mass flow rate & $0.000668 \mathrm{~kg} / \mathrm{s}$ \\
\hline
\end{tabular}

\section{Grid study and verification of the results}

In order to conduct the grid independency test we study the effect of grid resolution on the variation of velocity on the centerline. Velocity is an important and sensitive variable in the warm spray gun, and it is important to make sure that this variable is not affected by grid resolution. Hence, three grids with 14100, 54760 (taken from Khan and Shamim [30]) and 129420 cells are used to study the grid independency. Our analysis reveals that grid with 14100 cells provided results with non-physical fluctuations mainly in the barrel. However, results for a grid with 54760 cells are completely logical and the difference between the gas phase velocity for grids with 54760 and 129420 cells is less than $3 \%$. It should be mentioned that the percentage of error for the velocity of particle phase is much less than those obtained for the gas phase. Thus, the grid with 54760 cells is utilized for the rest of the computations.

For validation purposes, the computed temperature and velocity of the particle phase are compared to those of Khan and Shamim [30]. Fig. 4 depicts a good agreement between the present numerical results with those of Ref. [30]. 


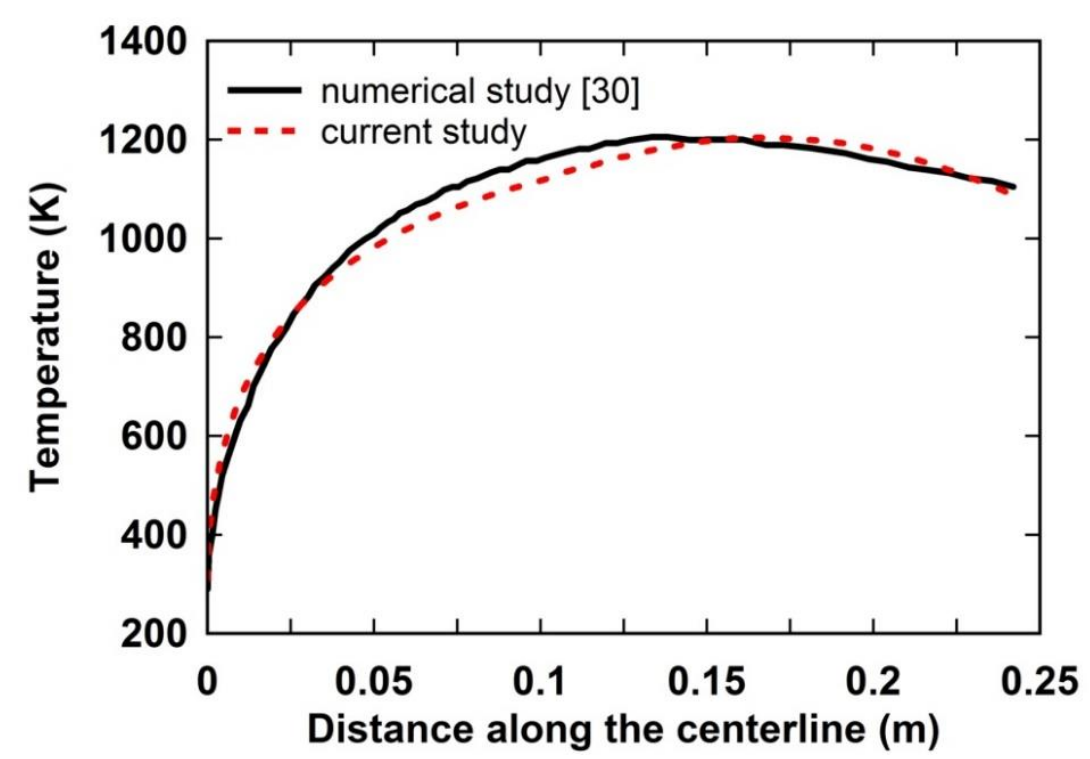

(a)

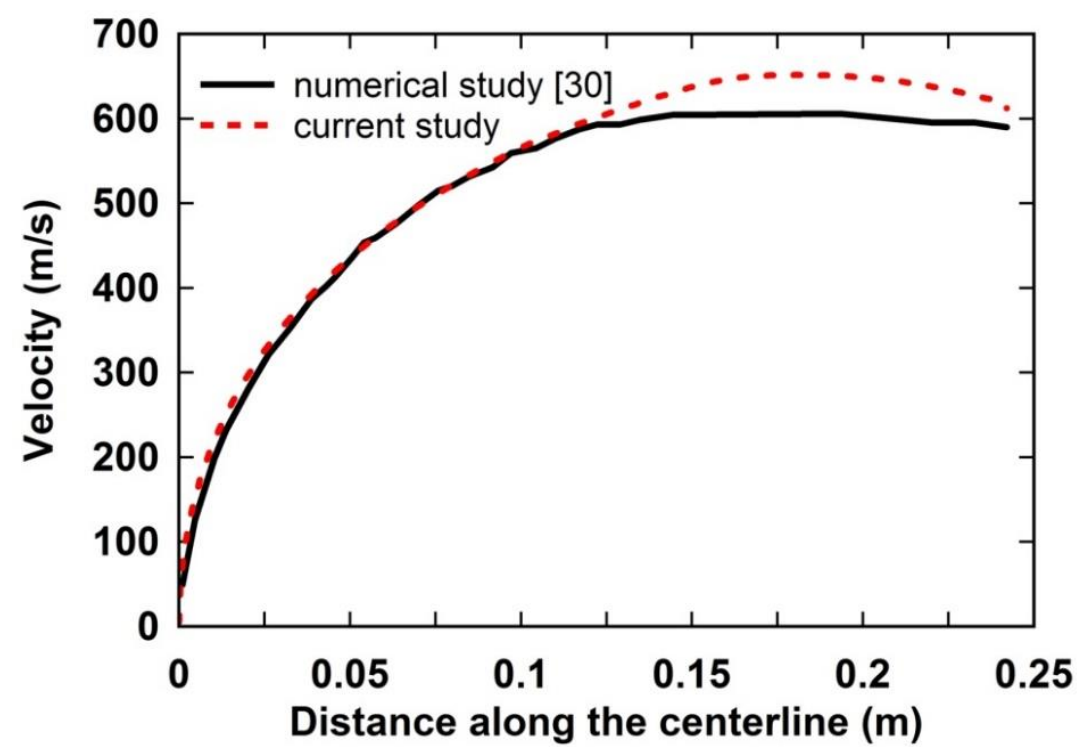

(b)

Fig. 4. Comparison of (a) temperature and (b) velocity of the particle phase as a function of distance along the centerline obtained in the present work against the numerical results of Ref. [30].

\section{Effect of coupled solution on the particle properties}

In a study by Yang and Eidelman [42], it is commented that since the particle mass flow rate is less than $4 \%$ of continuous phase mass flow rate, the effect of particle loading on the continuous phase is minimal. Therefore, the momentum and heat exchange from particle to the gas phase can be neglected and the particle phase can be decoupled from the gas phase. This approach was used to simulate particle motion and temperature in several numerical investigations of HVOF and warm spray guns (e.g. [3, 11, 16, 27, 30, 42]). To examine this assumption, the current study considers the effect of interphase momentum and heat exchange on the particle phase behavior. The results are presented in Figs. 5 and 6. The effect of coupled solution and particle loading on the particle temperature and velocity is shown in Fig. 5. The particles enter the gun at the barrel entrance and path along the centerline until reach to the end of the computational domain. Also, Fig. 6 displays the effect of particle loading on the particle temperature and velocity at barrel exit. 


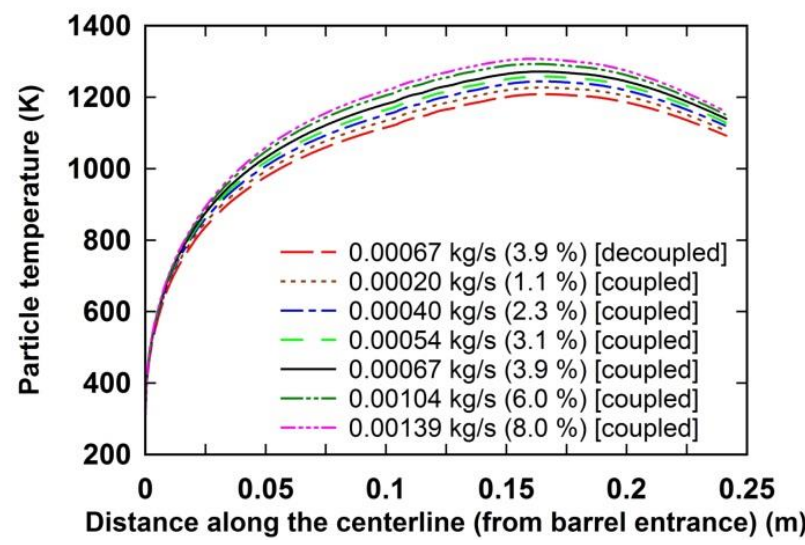

(a)

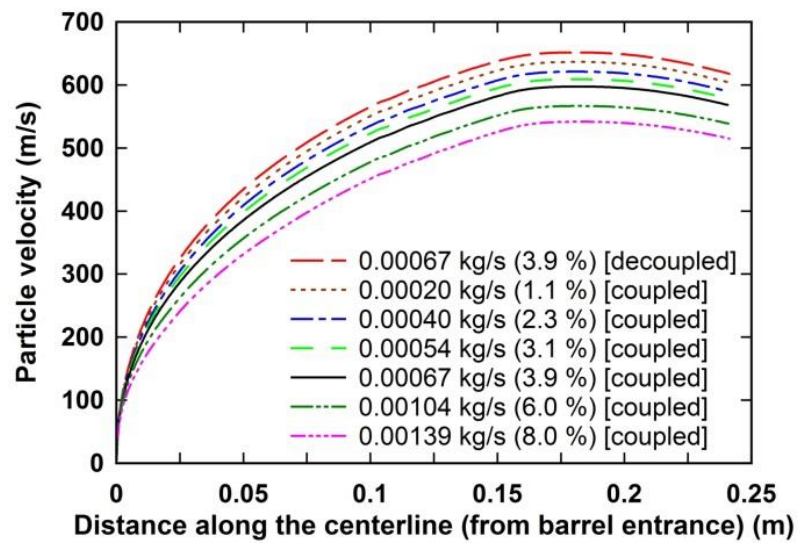

(b)

Fig. 5. Effect of particle mass flow rate on the particle (a) temperature and (b) velocity.

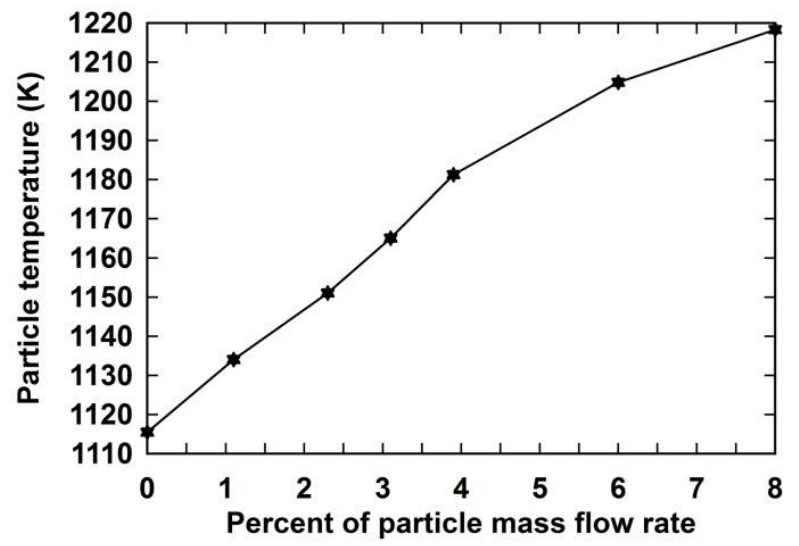

(a)

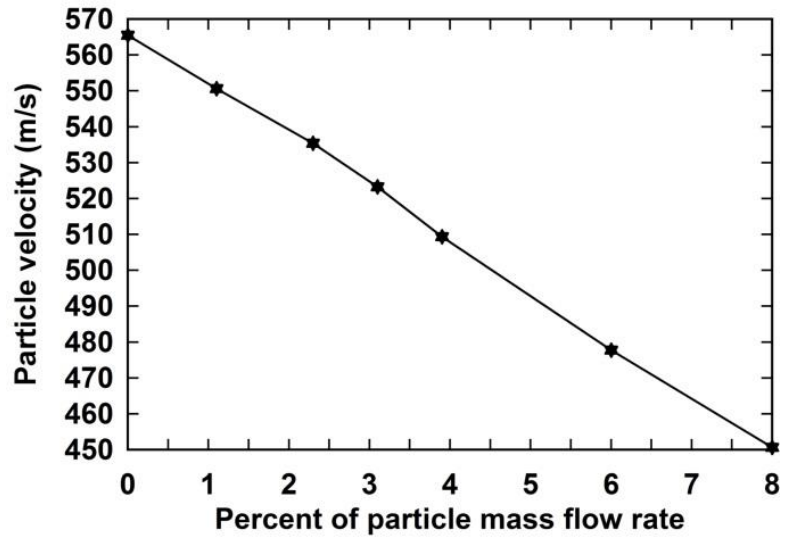

(b)

Fig. 6. Effect of particle mass flow rate on the particle (a) temperature and (b) velocity at barrel exit.

These figures reveal two important facts about the interaction between the two phases. Firstly, Fig. 6 shows that for percent of particle mass flow rate lower or higher than $3.9 \%$, the velocity and temperature of the particle have a linear dependency to the percent of particle mass flow rate. It seems that the $4 \%$ particle loading is not an exact criterion for decoupling particle and gas dynamic. Secondly, as it is seen in Figs. 5 (a) and 6 (a), for a fixed particle mass flow rate (i.e. 3.9\%) the particle temperature at barrel exit predicted using decoupled solution is almost $5 \%$ lower than that obtained for a coupled solution. Moreover, Figs. 5 (b) and 6 (b) show that at the barrel exit, the particle velocity based on the decoupled solution is almost $10 \%$ higher than that of the coupled solution. This further clarifies the role of coupled solution in accurate molding of flow in the warm spray. Thus, in the present work the effect of particle on the continuous phase is considered for all cases studied.

\section{Results and discussion}

\subsection{Analysis of gas dynamic and particle behavior}

Fig. 7 shows the variation of velocity and temperature of the particle and gas phases along the centerline which is obtained for the base case given in Table 1. In warm spray system the 
combustion chamber temperature increases due to combustion process. This high level of internal energy converts to kinetic energy when the exhaust gases accelerate through a converging nozzle. It can be seen in Fig. 7(a) that the flow experiences $350 \mathrm{~m} / \mathrm{s}$ increase in velocity when it passes through the converging nozzle. By the next step, nitrogen is added to flow in mixing chamber to cool down the flow. In this stage, velocity and pressure remain roughly constant on the centerline, but the increasing rate of temperature decreases. Then, in C-D nozzle, the flow accelerates and becomes supersonic. Therefore, the flow experiences a drastic decline in pressure and temperature.

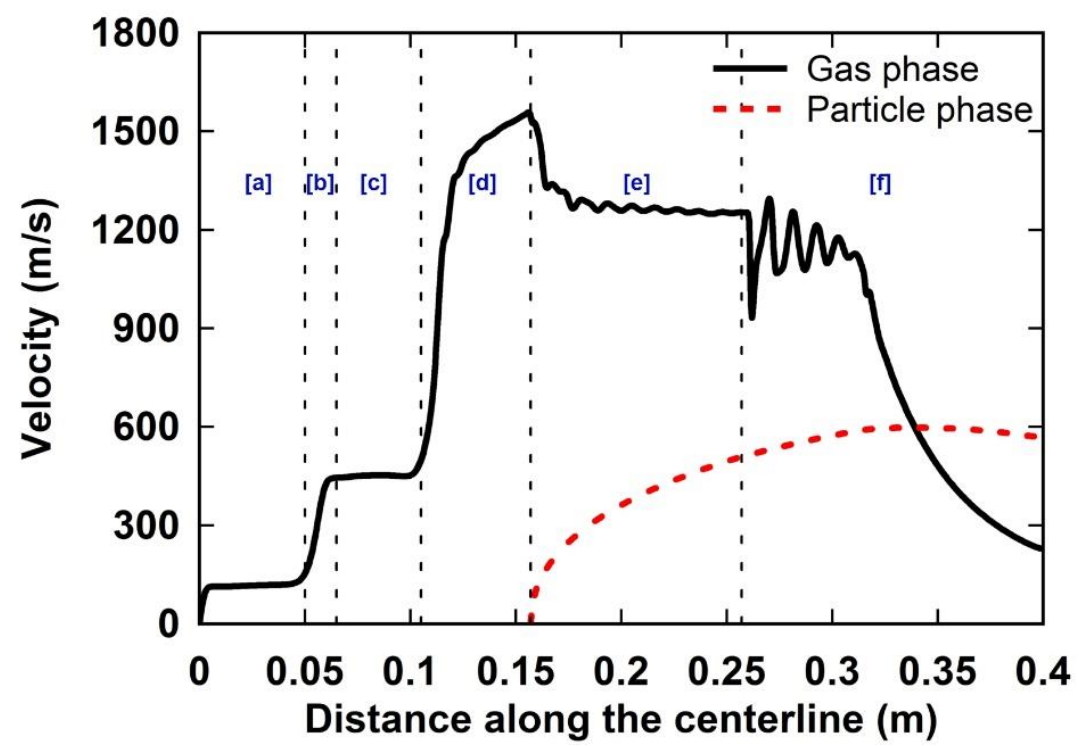

(a)

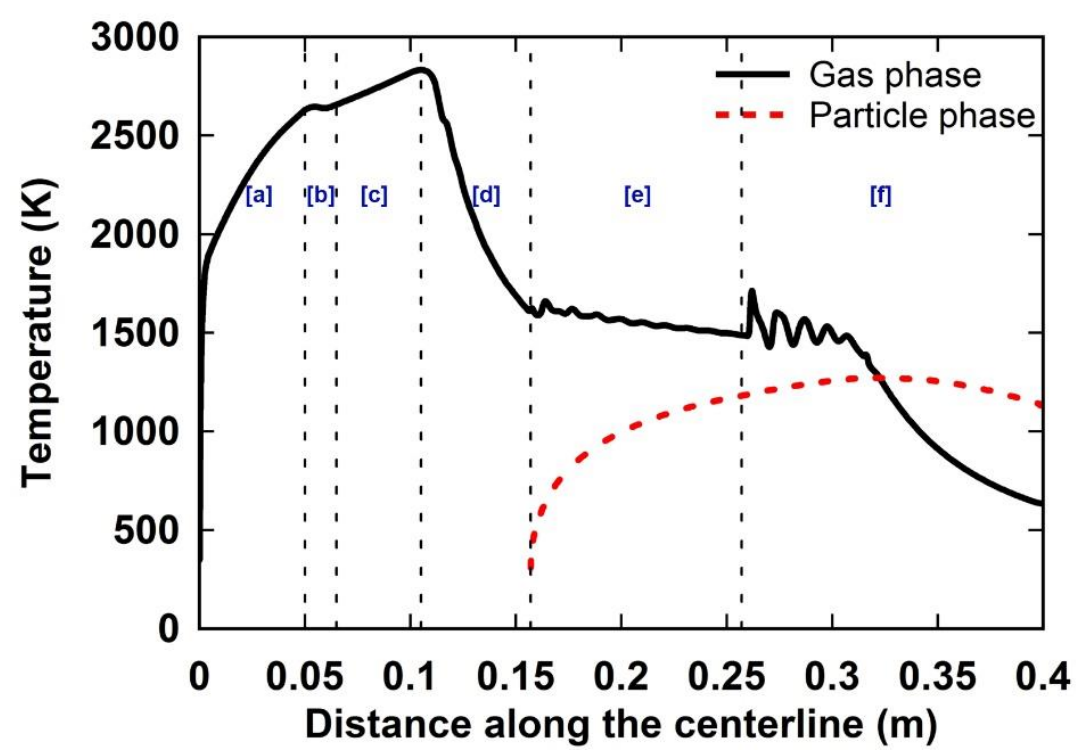

(b)

Fig. 7. Distribution of (a) velocity and (b) temperature as a function of distance along the centerline obtained for the base case for gas phase (solid line) and particle phase (dotted line). [a], [b], [c], [d], [e] and [f] indicate combustion chamber, converging nozzle, mixing chamber, C-D nozzle, barrel and outside atmosphere, respectively.

Fig. 8 presents the contours of velocity and temperature in the computational domain. It is seen when the supersonic flow enters the barrel, it passes through a series of incident and reflected oblique shock waves. This shock structure results in the small fluctuations in velocity and temperature in the barrel as can be seen in Fig. 7. However, both velocity and temperature remains 
almost constant through the barrel (Fig. 7). When the flow comes out of the barrel, the exhaust supersonic jet has a boundary surface which interfaces with the surrounding quiescent atmospheric air [46]. This free boundary reflects an incident shock wave as an expansion wave and vice versa. Therefore, the diamond-like wave patterns with compression and expansion waves form at downstream of the barrel exit. This complicated structure causes the gas velocity and temperature to undergo a series of fluctuations as seen in Fig. 7.

It is further seen in Fig. 7 that the velocity and temperature of the particle phase increase drastically along the centerline up to $\mathrm{x}=0.20 \mathrm{~m}$. Then a monotone increase in the particle velocity and temperature are observed up to $x=0.34 \mathrm{~m}$ and $\mathrm{x}=0.32 \mathrm{~m}$, respectively. It means that the particle obtains its peak temperature and velocity outside of the gun. These maximum values for the base case are $597.5 \mathrm{~m} / \mathrm{s}$ and $1271.7 \mathrm{~K}$. Then slight decreases in these properties are observed until the exit of the computational domain. After the particle reaches to its peak temperature, the direction of heat transfer changes, and heat transfers from the particle to the gas flow.

From Fig. 7 (a) it is obvious that when the particles are injected to the gun (i.e. barrel entrance), the gas velocity decreases sharply. This behavior was not observed in the previous simulations of warm spray process (e.g. $[16,30])$. This can be attributed to the interaction between particle and flow in a two-way coupling manner.

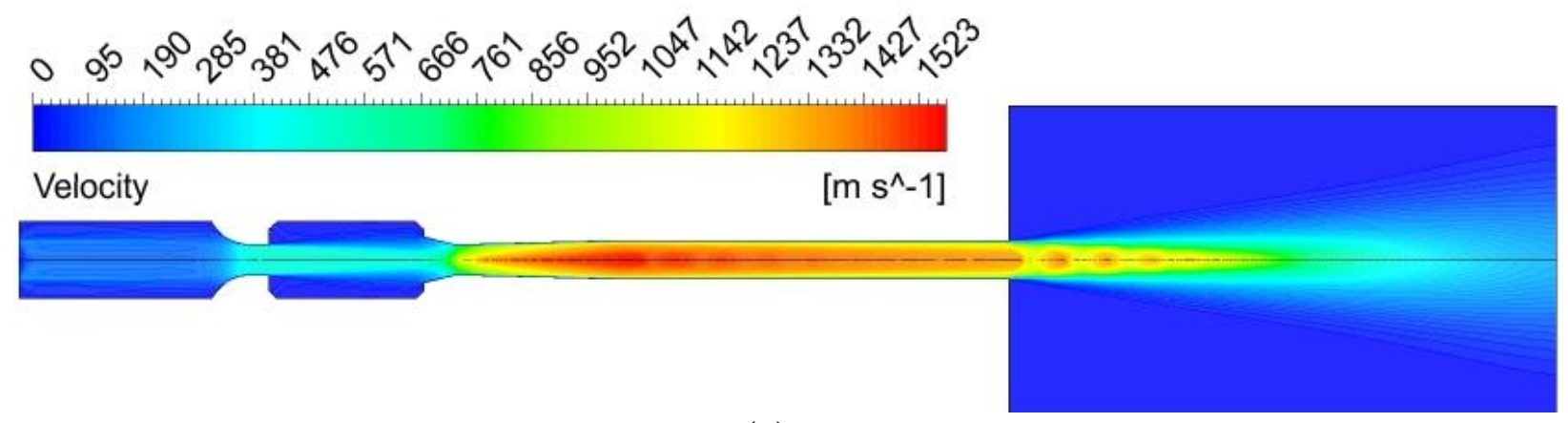

(a)

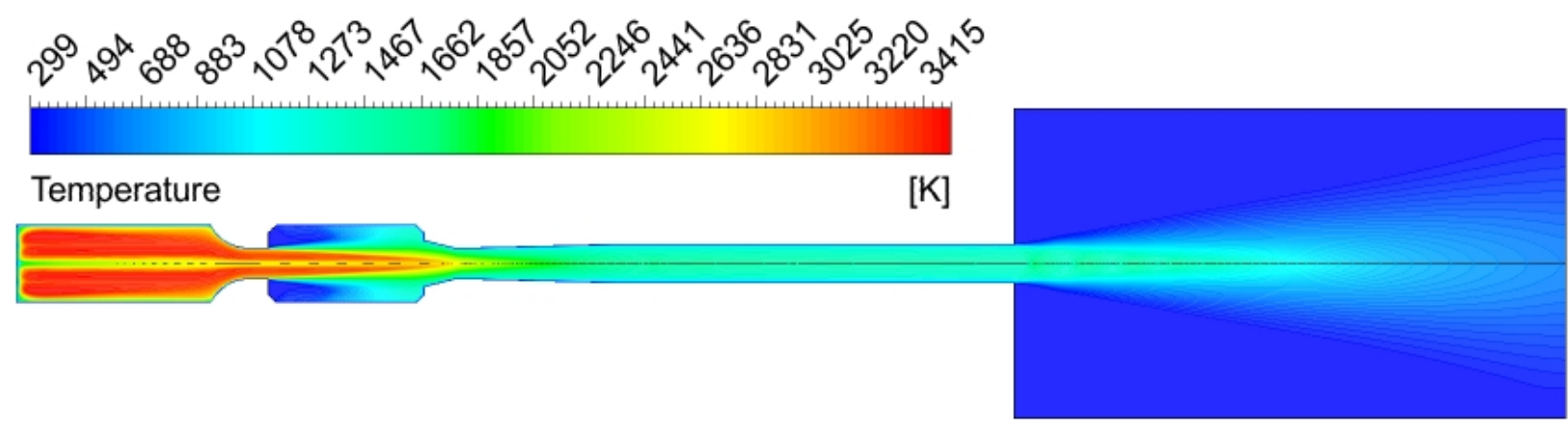

(b)

Fig. 8. Contour of (a) velocity and (b) temperature of the gas phase for the base case.

389 The following sections discuss the effect of four important geometrical design parameters on the 390 performance of the warm spray guns.

\subsection{Effect of converging nozzle throat diameter}


Fig. 9 shows the effect of throat diameter of the converging nozzle on the gas and particle phases' properties. According to Table 1, Case 1 and Case 2 have $1^{\text {st }}$ nozzle throat diameters smaller than the base case while Case 3 has a diameter higher than the base case. Fig. 9 shows that the throat diameter of $1^{\text {st }}$ nozzle does not have significant effect on the flow velocity and temperature upstream of the nozzle while it causes remarkable changes on the flow in the downstream of the nozzle. Up to $x=0.157 \mathrm{~m}$ (the barrel entrance), the gas phase velocity is affected by the nozzle throat diameter. Reduction of the first nozzle diameter increases the pressure in the combustion chamber, and reduces the pressure and increases the gas velocity in the mixing chamber. In contrast, this change does not affect these variables in the barrel since the stagnation pressure in the mixing chamber is the same for all cases. Therefore, the gas velocity in the barrel does not change with the throat diameter while the gas temperature experiences noticeable changes. Since the flow velocity and pressure at barrel exit are almost equal for all cases, the diamond-like jets at barrel exit, which are visible as fluctuations in Fig. 9, look similar. Fig. 9 shows that increasing the $1^{\text {st }}$ nozzle throat diameter has no remarkable effect on the particle velocity while this change has a substantial effect on the particle temperature. It can be concluded that the behavior of the gas properties have the same effects on the particle properties. It is an interesting finding that changing the diameter of converging nozzle serves a powerful control over the particle temperature while the particle velocity remains intact. Based on the results presented in Fig. 9 (b), 33\% decrease in the nozzle throat diameter (comparison between Case 1 and Case 3) causes $11 \%$ decline in the particle temperature at the end of the computational domain. The decrease in the gas phase and particle temperature is due to the fact that by reducing the diameter of converging nozzle the turbulent behavior of flow in the mixing chamber and C-D nozzle increases. This enhances the turbulent mixing of hot gases and cold nitrogen.

To evaluate of the effect of turbulent mixing, the variation of the turbulent intensity along the centerline is given in Fig. 10 for all above cases. As it is seen, Case 1 (related to minimum nozzle diameter) has the highest level of turbulent intensity in the mixing chamber and C-D nozzle. For this case, the turbulent intensity increases due to a stronger jet-like flow which passes through the converging nozzle resulting in a more strained shear layer. The increase of turbulent intensity enhances the turbulent mixing of hot combustion products and nitrogen cooling gas.

To show the effect of turbulent mixing on the radial diffusion of nitrogen, the radial distribution of $\mathrm{N}_{2}$ mole fraction at the barrel entrance (the location of particle injection) is presented in Fig. 11 (a). It is seen that the radial distribution of $\mathrm{N}_{2}$ in Case 1 is more uniform at barrel entrance. It means that the higher level of turbulent mixing can lead to an increase of radial diffusion of nitrogen. Also, the cooling effect of nitrogen results in a more uniform distribution of radial temperature. The uniform radial distribution of temperature shows its practical importance when the particles get away from the centerline. The radial distance of particle from the centerline determines the degree of heating and melting of the particles. As the particles get away from the centerline, their temperature decreases [3]. In fact, a radial uniformity in gas phase temperature results in an uniformity of the particle temperature regardless of particles' radial distance from the centerline.

The effect of throat diameter of the $1^{\text {st }}$ nozzle on the variation of radial $\mathrm{O}_{2}$ distribution at $63 \mathrm{~mm}$ outside of barrel (i.e. $x=320 \mathrm{~mm}$ where the particles typically attain their highest temperature) is depicted in Fig. 11 (b). In practice, radial distribution of oxygen determines the oxidant content of particles at the point of impact on the substrate and consequently the coating quality. It can be seen 
that the radial $\mathrm{O}_{2}$ distributions are the same for all cases. The oxygen content of the jet flow in the atmosphere is mostly resulted from jet velocity at barrel exit because the flow with higher velocity at barrel exit faces higher turbulent intensity and higher turbulent mixing with ambient air. Therefore, roughly same velocity at barrel exit (Fig. 9 (a)) leads to the same level of turbulent intensity (Fig. 10) and radial oxygen content (Fig. 11 (b)).

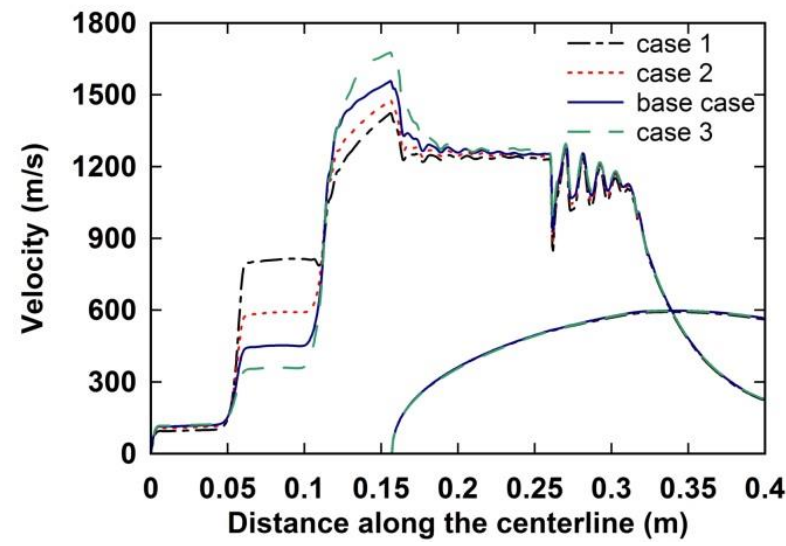

(a)

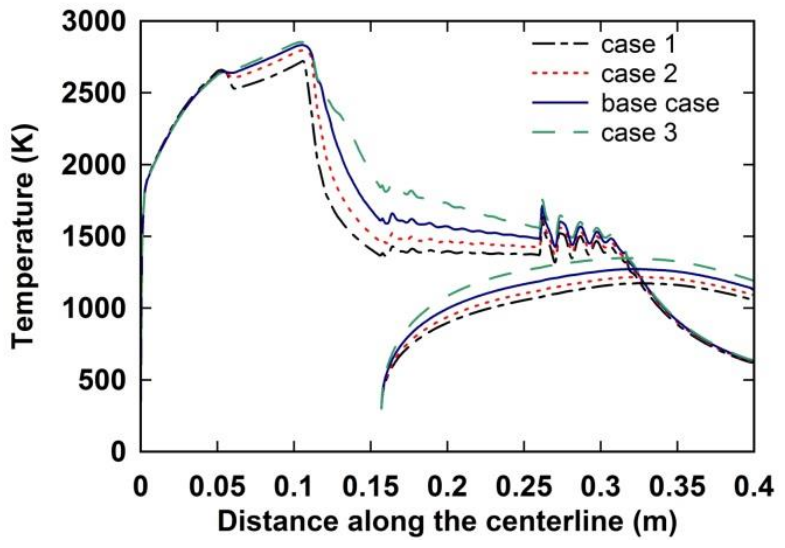

(b)

Fig. 9. Effect of throat diameter of the $1^{\text {st }}$ nozzle on the variation of (a) velocities and (b) temperatures of the gas and particle phases along the centerline.

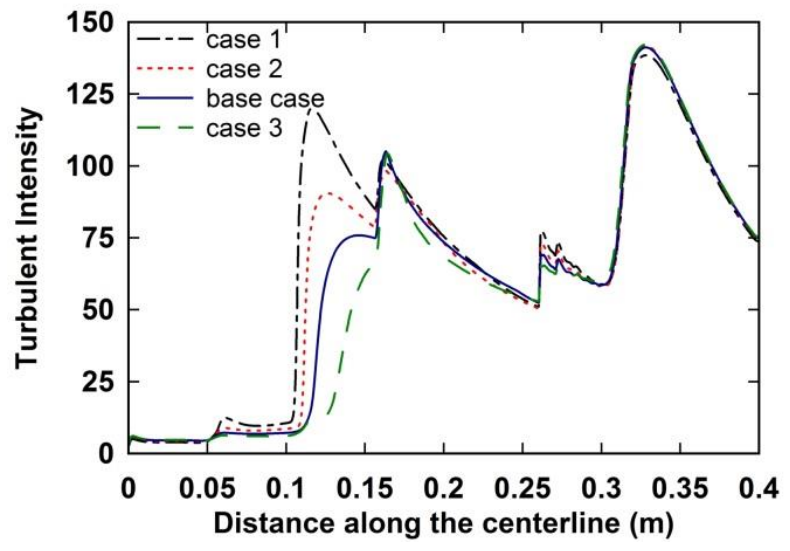

Fig. 10. Effect of throat diameter of the $1^{\text {st }}$ nozzle on the variation of turbulent intensity of flow along the centerline.

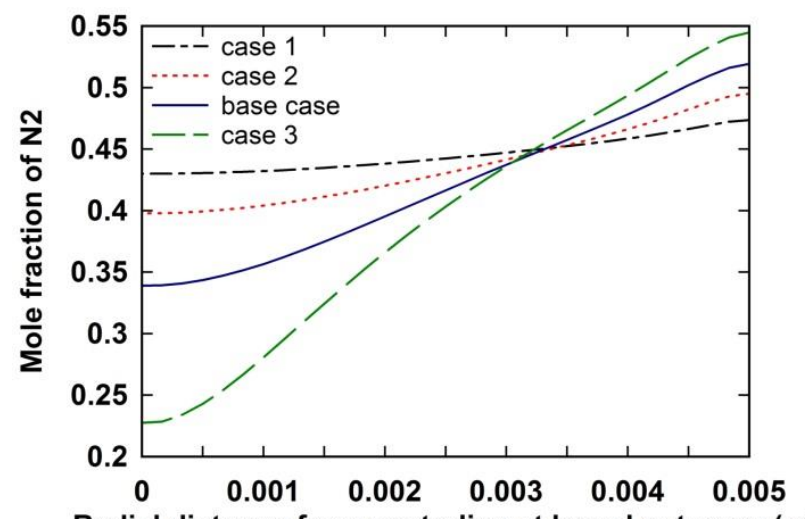

Radial distance from centerline at barrel entrance $(\mathrm{m})$

(a)

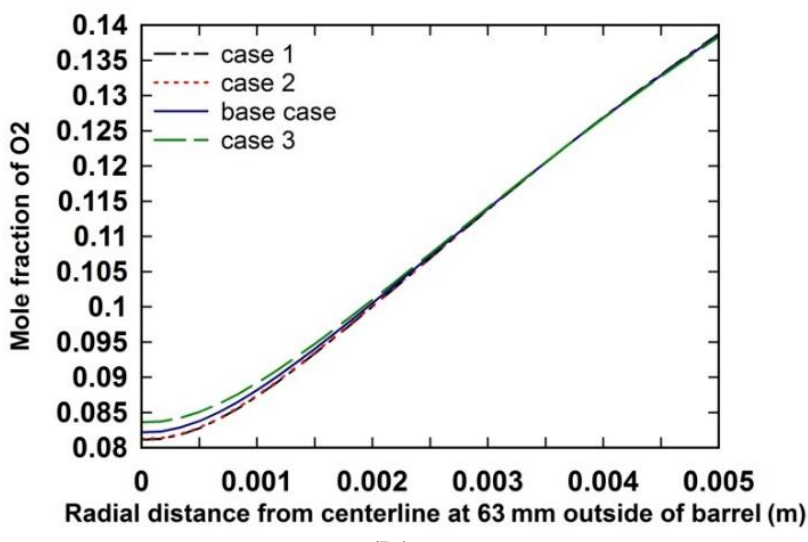

(b) 
Fig. 11. Effect of throat diameter of the $1^{\text {st }}$ nozzle on the variation of (a) nitrogen radial distribution at the barrel entrance and (b) oxygen radial distribution at $63 \mathrm{~mm}$ outside of the barrel (i.e. $\mathrm{x}=320 \mathrm{~mm}$ ).

440

441

442

443

444

445

446

447

448

449

450

451

452

453

454

455

456

457

458

459

460

461

462

463

464

465

466

467

468

469

470

471

472

473

474

475

476

477

\subsection{Effect of C-D nozzle throat diameter}

The impact of C-D nozzle throat diameter in a liquid-fueled single stage HVOF gun was studied by Tabbara et al. [44]. The current paper studies the impact of this parameter in a gas-fueled warm spray. Fig. 12 presents the velocity and temperature of gas and particle phases due to a change in the throat diameter of the second nozzle. According to Table 1, Case 4 and Case 5 have $2^{\text {nd }}$ nozzle throat diameters smaller than the base case while Case 6 has a diameter higher than the base case. Changing this parameter does not affect the flow velocity upstream of the throat in the single-stage HVOF gun. This was observed in the study by Tabbara et al. [44]. Nonetheless, changing the $2^{\text {nd }}$ nozzle throat diameter has remarkable effect on the upstream velocity of gas, especially in the mixing chamber. As it can be seen in Fig. 12 (a), decrease in C-D nozzle throat diameter results in a reduction of gas velocity in the combustor and mixing chamber. Similar to the single stage, in the dual stage HVOF, a decrease in C-D nozzle throat increases gas velocity and consequently the particle velocity in the downstream of the nozzle throat. An increase of the throat diameter reduces the stagnation pressure in the mixing chamber. Thus, further increase in the throat diameter (i.e. Case 6 in Table 1) causes the flow to expand normally through the nozzle and barrel. This is why no shock structure is seen in Fig. 12 (a) at the barrel exit (dashed green lines in Figs. 12 (a) and (b)).

From Fig. 12 (b) it is obvious that by increasing the C-D nozzle diameter, the particle temperature increases from Case 4 to Case 6. The particle temperature is influenced by the gas phase temperature and the residence time of particles in the barrel. Therefore, the increase in the particles temperature from Case 4 to Case 6 is due to both higher gas phase temperature and lower particle velocity (i.e. higher residence time). Based on Fig. 12 (b), 33\% decrease in the nozzle throat diameter (going from Case 4 to Case 6) causes $10 \%$ decline in the particle temperature and $9 \%$ decline in the gas temperature at the end of the computational domain.

Fig. 13 shows the effect of C-D nozzle throat diameter on the turbulent intensity of the flow. As it is mentioned above, the level of turbulent intensity in the mixing chamber and C-D nozzle determines the radial distribution of nitrogen, and consequently, distribution of temperature in the barrel. Compared to the other cases, the turbulent intensity of Case 6 in mixing chamber and C-D nozzle is the highest one. Therefore, in this case the radial distribution of nitrogen (see Fig. 14 (a)), and consequently, the temperature distribution is more uniform. Also the oxygen content of flow outside the barrel is influenced by the turbulent intensity caused by the jet velocity. Therefore, as it is seen in Fig. 14 (b), the highest oxygen content at this region occurs in Case 4 with the highest jet velocity at barrel exit. This increases the peril of oxidation in this case. In a study by Tabbara et al. [44], it was found that $20 \%$ reduction in C-D nozzle throat of single stage HVOF resulted in $60 \%$ increase in the pressure of combustion chamber. The current work shows that $20 \%$ decline in C-D nozzle throat causes $65 \%$ increase in gauge pressure of the combustion chamber. Hence, the impact of C-D nozzle throat diameter on combustion chamber pressure for single and dual HVOF is the same. 


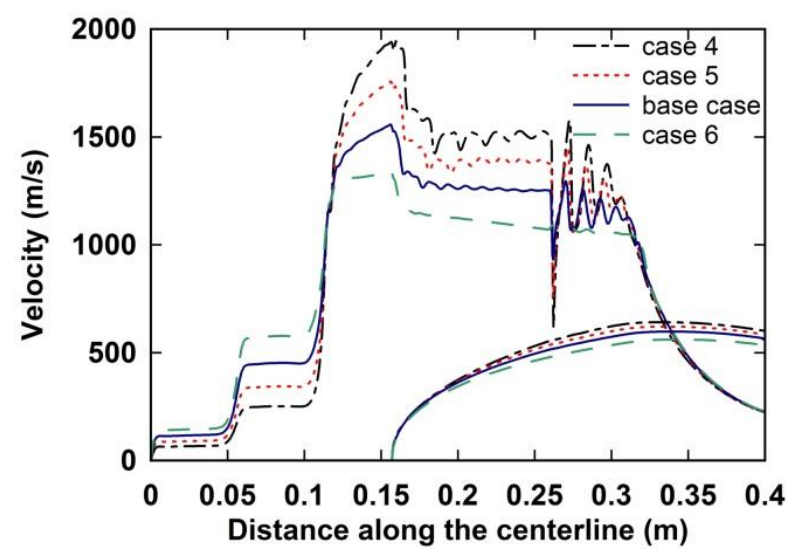

(a)

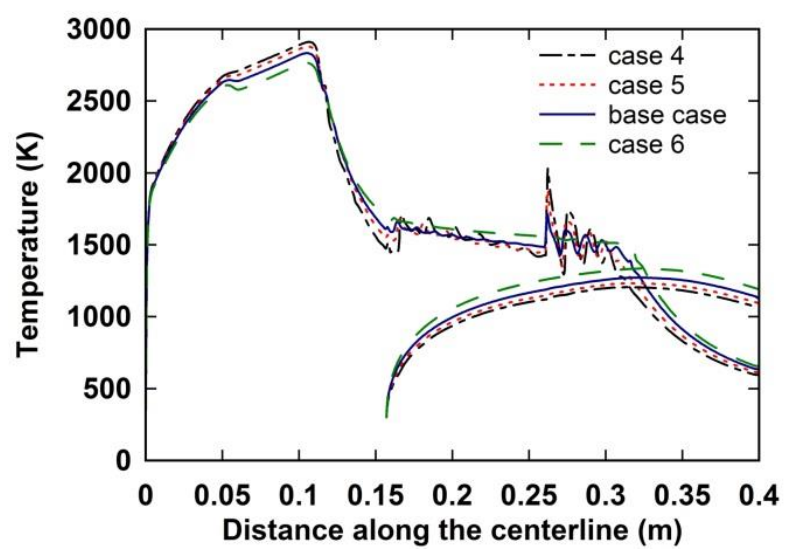

(b)

Fig. 12. Effect of throat diameter of the $2^{\text {nd }}$ nozzle on the variation of (a) velocities and (b) temperatures of the gas and particle phases along the centerline.

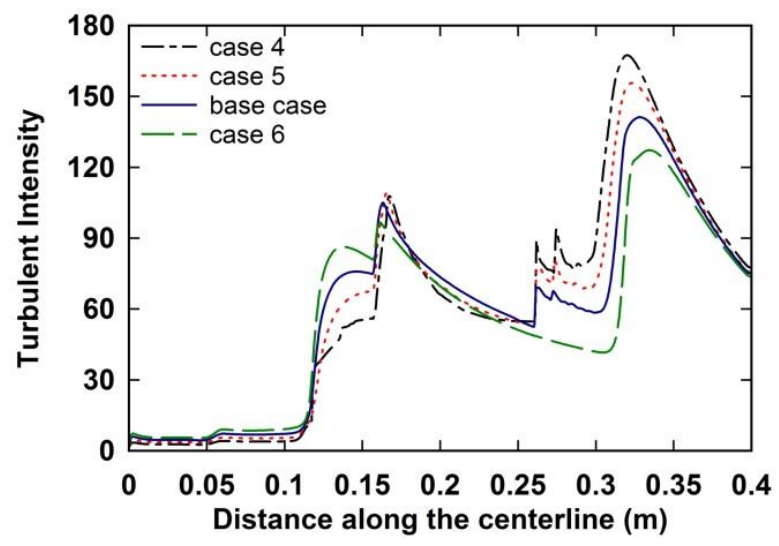

Fig. 13. Effect of throat diameter of the $2^{\text {nd }}$ nozzle on the variation of turbulent intensity of flow along the centerline.

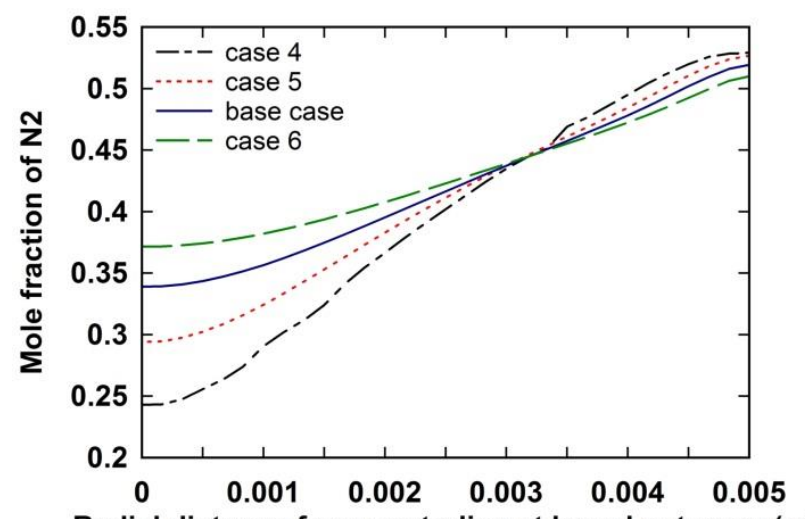

Radial distance from centerline at barrel entrance $(\mathrm{m})$

(a)

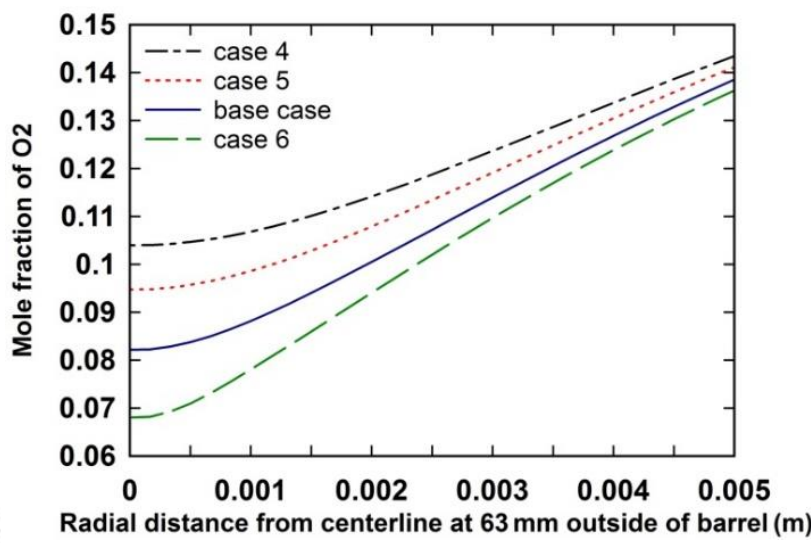

(b)

Fig. 14. Effect of throat diameter of the $2^{\text {nd }}$ nozzle on the variation of (a) nitrogen radial distribution at the barrel entrance and (b) oxygen radial distribution at $63 \mathrm{~mm}$ outside of the barrel (i.e. $x=320 \mathrm{~mm}$ ).

\subsection{Effect of changing the diameters of both converging and C-D nozzles}

479 The effects of throat diameters of both converging $\left(1^{\text {st }}\right)$ and C-D $\left(2^{\text {nd }}\right)$ nozzles on the gas and particle dynamic are studied in this section. Fig. 15 presents the velocity and temperature of gas 
and particle phases due to a simultaneous change in the $1^{\text {st }}$ and $2^{\text {nd }}$ nozzle throat diameters. According to Table 1, for Case 7 and Case 8 the throat diameters of both nozzles are smaller than the base case while for Case 9 the nozzles have throat diameters higher than the base case. The results presented in this section show that increasing the diameter of the two nozzles to a same level, lessens or intensifies the effect of increasing diameter of each nozzle that we observed in the previous sections.

To explain the effect of this geometric modification on particle velocity, we further inspect Figs. 9 (a), 12 (a) and 15 (a). In Fig. 9 (a), it is seen that an increase in the $1^{\text {st }}$ nozzle throat diameter causes a very slight increase in the velocity (i.e. from $561 \mathrm{~m} / \mathrm{s}$ to $567 \mathrm{~m} / \mathrm{s}$ ). However, Fig. 12 (a) shows that an increase in the $2^{\text {nd }}$ nozzle throat diameter results in a noticeable decrease in the particle velocity (from $600 \mathrm{~m} / \mathrm{s}$ to $535 \mathrm{~m} / \mathrm{s}$ ). In Fig. 15 (a) it is seen that simultaneous increase of the $1^{\text {st }}$ and $2^{\text {nd }}$ nozzle throat diameters, decreases the velocity of the particle from $595 \mathrm{~m} / \mathrm{s}$ to 536 $\mathrm{m} / \mathrm{s}$.

The velocity ranges given above show that the decrease in the particle velocity of the third geometrical group (see Table 1) is less severe than the second group. This is because increasing the first nozzle throat diameter has a slight increasing effect on the particle velocity.

This conclusion can also be taken by analyzing the temperature field. Fig. 9 (b) shows that an increase in the converging nozzle throat diameter increases the particle temperature by $135 \mathrm{~K}$. Fig. 12 (b) also shows that an increase in the C-D nozzle throat diameter increases the particle temperature by 127 K. In Fig. 15 (b) we can see that simultaneous increase in the both nozzle throat diameters increases the particle temperature by $274 \mathrm{~K}$. Thus, it is concluded that simultaneous increase in the both nozzle diameters intensifies separate effects of these changes, and it can provide us with the particle temperatures twice wider than the range of particle temperature in the first and second groups of models.

Fig. 16 shows the variation of turbulent intensity along the center line due to simultaneous change of diameters for the $1^{\text {st }}$ and $2^{\text {nd }}$ nozzles. It is seen that increasing the diameters of the two nozzles (from Case 7 to Case 9 in Table 1) doesn't noticeably affect the turbulent intensity in the combustion chamber, converging nozzle and mixing chamber (i.e. $0<x<0.105 \mathrm{~m}$ ). On the other hand, in the convergent section of the C-D nozzle the turbulence level is more for Case 7. Therefore, as it can be seen in Fig. 17 (a) the radial distribution of nitrogen and consequently temperature in the barrel is more uniform in Case 7.

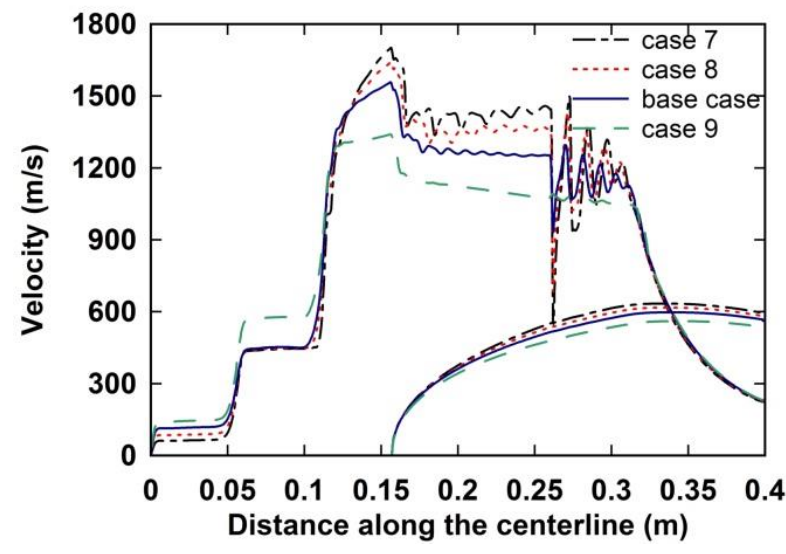

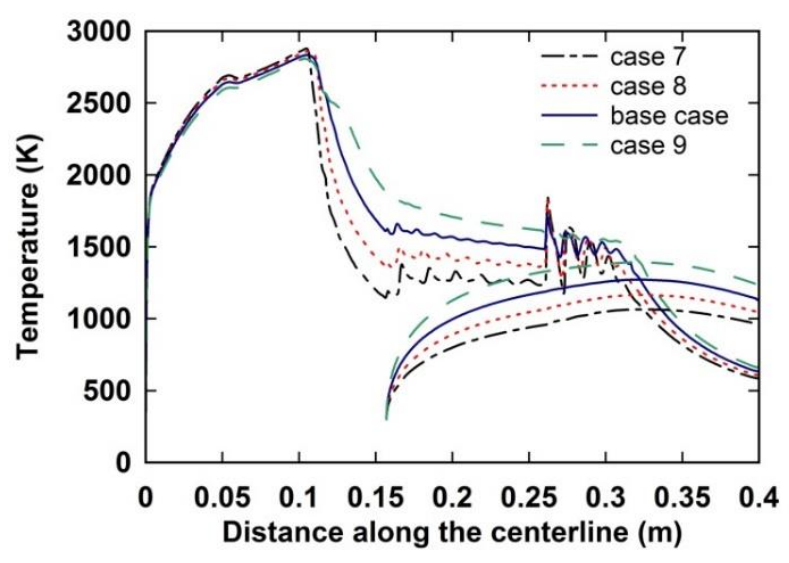


Fig. 15. Effect of changing throat diameter of both $1^{\text {st }}$ and $2^{\text {nd }}$ nozzles on the variation of (a) velocities and (b) temperatures of the gas and particle phases along the centerline.

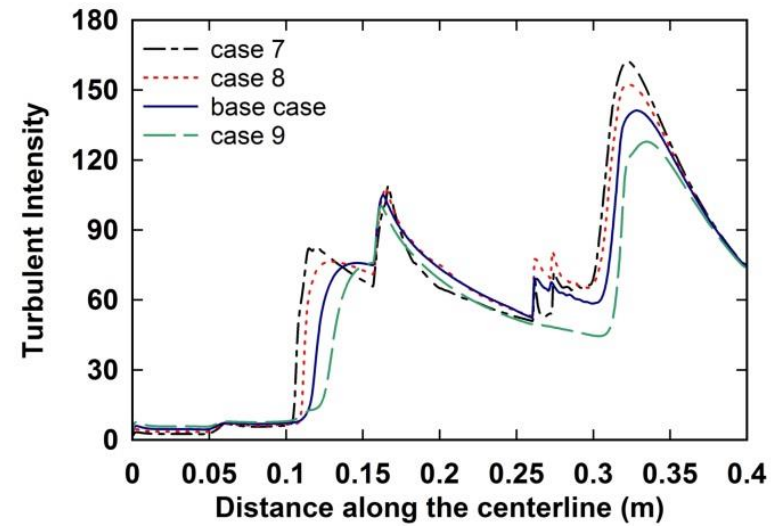

Fig. 16. Effect of changing throat diameter of both $1^{\text {st }}$ and $2^{\text {nd }}$ nozzles on the variation of flow turbulent intensity along the centerline.

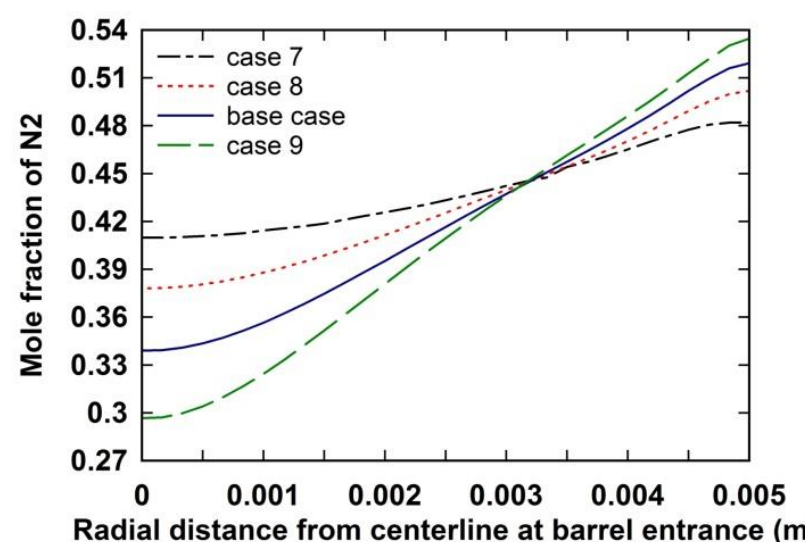

(a)

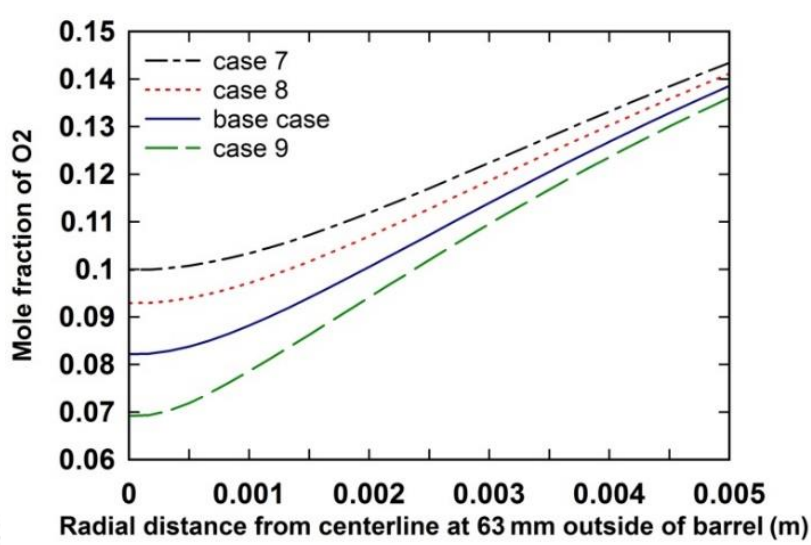

(b)

Fig. 17. Effect of changing throat diameter of both $1^{\text {st }}$ and $2^{\text {nd }}$ nozzles on the variation of (a) nitrogen radial distribution at barrel entrance and (b) oxygen radial distribution at $63 \mathrm{~mm}$ outside of the barrel (i.e. $\mathrm{x}=320 \mathrm{~mm}$ ).

Fig. 17 (b) also shows the effects of this geometrical change on the radial distribution of oxygen outside the barrel. The results of oxygen mole fraction and turbulent mixing outside the barrel roughly follow what is discussed in the previous parts.

\subsection{Effect of the length of divergent section in the C-D nozzle}

In this section we study the effect of the length (L) of the divergent section of the C-D nozzle on the velocity, temperature and turbulent intensity of the two phases. With a fixed divergent angel, a longer divergent section of the $\mathrm{C}$-D nozzle gives the gas phase a chance to reach a lower pressure and temperature and consequently higher velocity when it enters the barrel. Fig. 18 shows the variations of the gas and particle velocity and temperature for different lengths of the divergent section. For Case 10 which the divergent section length is $\mathrm{L}=30 \mathrm{~mm}$, the flow expands normally to around 1 bar through the C-D nozzle and barrel. Thus, no shock wave is observed at the barrel exit. In contrast, in Case 13 with $\mathrm{L}=50 \mathrm{~mm}$, the flow over-expands in the C-D nozzle and sharpest series of oblique shocks occur. Fig. 18 (a) shows that while the gas velocity in Case 13 is higher 
than the other cases, the particle velocity of Case 13 is not more than other cases. The reason is that in this case the flow expands more through a longer divergent section, and the density of the flow and consequently the drag force of the flow acting on the particles decreases. This compensates the effect of higher gas velocity. Fig. 18 (b) shows that as the nozzle length increases, the flow temperature in the C-D nozzle decreases. Therefore, Case 13 in Fig. 18 (b) yields the minimum temperature among different cases. Thus, the gas temperature and consequently the particle temperature is lower than other cases in the barrel. Based on Fig. 18 (b), $40 \%$ decrease in L (comparison between Case 10 and Case 13) does not have significant effect on the temperatures of the particle and gas phases at the end of the computational domain.

534 Fig. 19 reveals the turbulent intensity of the flow on the centerline for cases 10 to 13. In Case 13, flow experiences higher speed and stronger shocks at barrel entrance, resulting in more strong stepwise increase in the turbulent intensity and mixing at the barrel entrance. Thus, as it is seen in Fig. 20 (a), the radial distribution of nitrogen at the barrel entrance is more uniform in Case 13. Fig. 20 (b) shows the radial concentration of the oxygen $63 \mathrm{~mm}$ outside of the barrel (i.e. $\mathrm{x}=320$ $\mathrm{mm}$ in Fig. 3). Roughly same gas phase velocity at the barrel exit leads to same oxygen content at 540 this section.

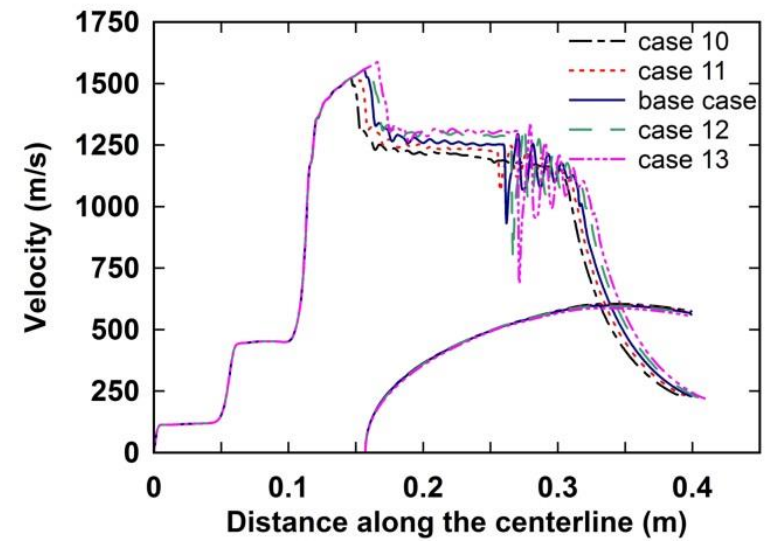

(a)

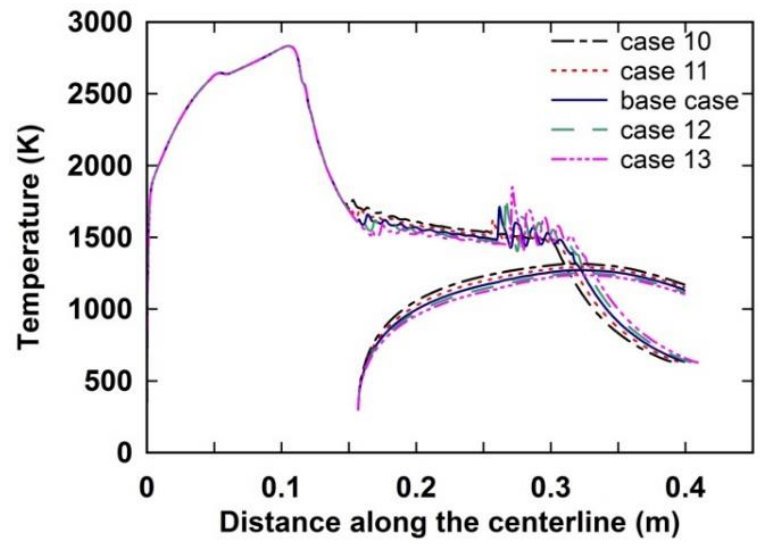

(b)

Fig. 18. Effect of divergent section of the C-D nozzle on the variation of (a) velocities and (b) temperatures of the gas and particle phases along the centerline. For better comparison the places of particle injection in all case are shifted to place of base case injection.

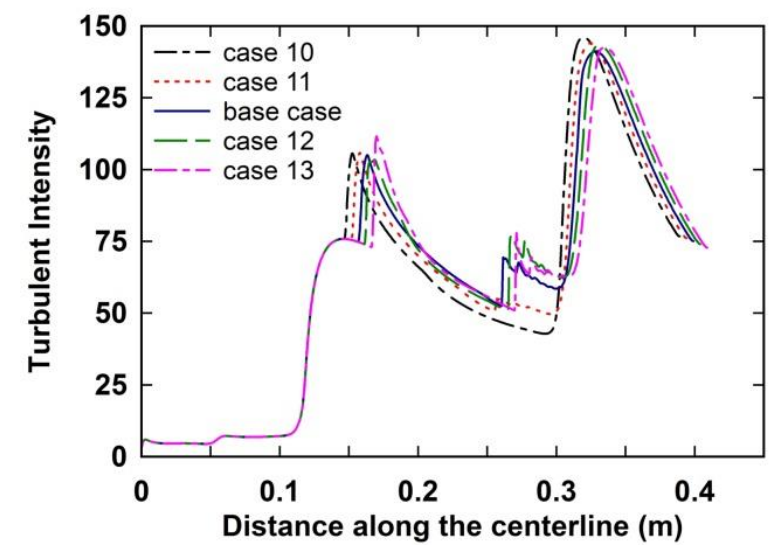

Fig. 19. Effect of divergent section of the C-D nozzle on the variation of turbulent intensity of flow along the centerline. 


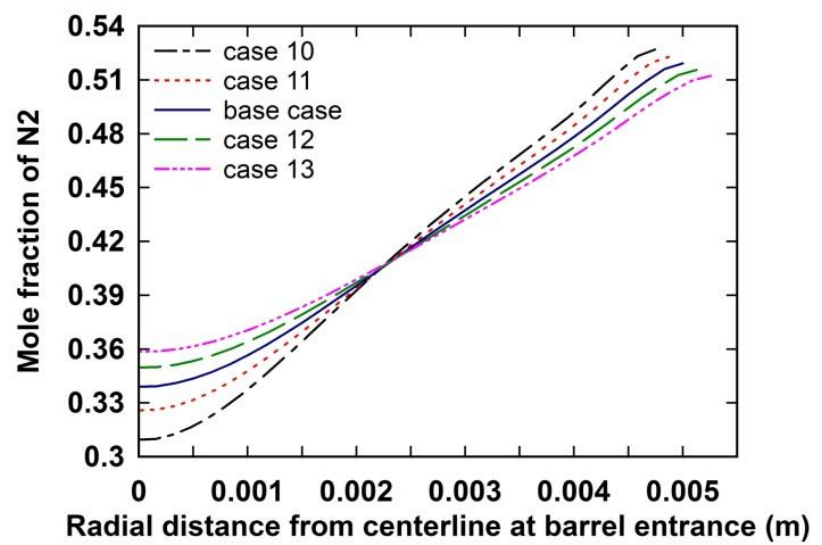

(a)

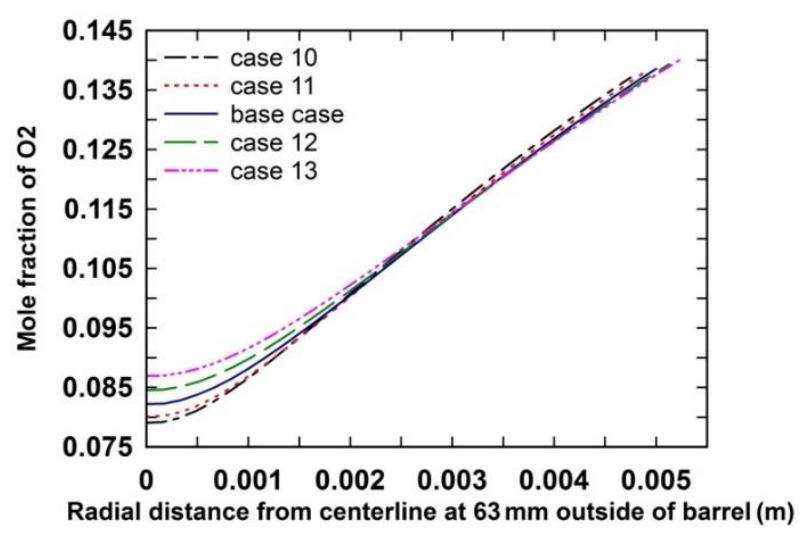

(b)

Fig. 20. Effect of divergent section of the C-D nozzle on the variation of (a) nitrogen radial distribution at the barrel entrance and (b) oxygen radial distribution at $63 \mathrm{~mm}$ outside of the barrel (i.e. $\mathrm{x}=320 \mathrm{~mm}$ ).

\section{Conclusions}

Considering the two-way interaction between gas and particle phases, we conducted a parametric study to investigate the effects of four geometric variables in a dual-stage HVOF thermal spray gun. The emphasis was placed on the effect of the first and second nozzles geometrical parameters on the physical properties such as velocity and temperature of the gas and particle phases. The major findings are as follows:

- Decouple modeling of the particle and the continuous phase causes a significant error in predicting the velocity of particle at the impact moment, even for low particle loads.

- In the first group, decreasing the first nozzle throat diameter results in higher turbulent mixing in the mixing chamber and C-D nozzle. It helps to achieve more uniform radial temperature in the barrel. This change does not affect the particle velocity and decreases the particle temperature. Hence, it can be considered as a way of controlling the particle temperature at a fixed velocity.

- In the second group, decreasing the C-D nozzle throat diameter reduces the particle temperature and increases its velocity. Moreover, it increases the oxygen content of the free jet outside of barrel and augments the risk of particle oxidation.

- In the third group, when the diameters of both nozzles are changed, the widest variety of particle temperature is achieved while the particle velocity remains roughly similar to those obtained for the second group.

- By increasing the length of the divergent section of C-D nozzle, the particle velocity does not changed. Therefore, this geometrical parameter can be taken as a way of controlling particle temperature by preserving its velocity.

\section{Funding sources}


This research did not receive any specific grant from funding agencies in the public, commercial, or not-for-profit sectors.

\section{Reference}

[1] D.M. Brunette, P. Tengvall, M. Textor, P. Thomsen. Titanium in Medicine: Material Science, Surface Science, Engineering, Biological Responses and Medical Applications, Springer, 2001.

[2] O.E. Pohler. Unalloyed titanium for implants in bone surgery, Injury, 2000, 31, p. 7-13.

[3] H. Tabbara, S. Gu, D.G. McCartney. Computational modeling of titanium particles in warm spray, Computers \& Fluids, 2011, 44, p. 358-368.

[4] R.R. Boyer. An overview on the use of titanium in the aerospace industry, Materials Science and Engineering: A, 1996, 213, p. 103-114.

[5] L. Pawlowski. The Science and Engineering of Thermal Spray Coatings, $2^{\text {nd }}$ ed., Wiley, 2008.

[6] M.J. Donachie. Titanium: a technical guide, $2^{\text {nd }}$ ed., ASM International, 2000.

[7] T. Bernecki. Surface science. In: J.R. Davis, editor. Handbook of Thermal Spray Technology, $1^{\text {st }}$ print, ASM International, 2004, p. 14-35.

[8] P.L. Fauchais, J.V.R. Heberlein, M.I. Boulos. Thermal Spray Fundamentals: From Powder to Part, $1^{\text {st }}$ print, Springer, 2014.

[9] S. Kuroda, J. Kawakita, M. Watanabe, K.H. Kim, R. Molak, H. Katanoda. Current Status and Future Prospects of Warm Spray Technology. In: N. Espallargas, editor. Future Development of Thermal Spray Coatings: Types, Designs, Manufacture and Applications, $1^{\text {st }}$ ed., Woodhead Publishing, 2015, p. 163-206.

[10] A. Dolatabadi, J. Mostaghimi, V. Pershin. Effect of a cylindrical shroud on particle conditions in high velocity oxy-fuel (HVOF) spray process, Journal of Materials Processing Technology, 2002, 137, p. 214-224.

[11] T. Shamim, C. Xia, P. Mohanty. Modeling and analysis of combustion assisted thermal spray processes, International Journal of Thermal Sciences, 2007, 46, p. 755-767.

[12] C. Ponticaud, A. Grimaud, A. Denoirjean, P. Lefort, P. Fauchais. Thermal spray 2001: New surfaces for a new millennium, Proceedings of the International Thermal Spray Conferences, Singapore, 2001.

[13] T. Wu, S. Kuroda, J. Kawakitam, H. Katanoda, R. Reed. Processing and properties of titanium produced by warm spraying, Proceedings of the 2006 International Thermal Spray Conference, Seattle, Washington, USA, 2006.

[14] M. Watanabe, C. Braunsa, M. Komatsu, S. Kuroda, F. Gärtner, T. Klassen, H. Katanoda. Effect of nitrogen flow rate on microstructures and mechanical properties of metallic coatings by warm spray deposition, Surface \& Coatings Technology, 2013, 232, p. 587-599. 
[15] A. Papyrin, V. Kosarev, S. Klinkov, A. Alkhimov, V.M. Fomin. Cold Spray Technology, $1^{\text {st }}$ ed., Elsevier Science, 2007.

[16] M.N. Khan, T. Shamim. Effect of operating parameters on a dual-stage high velocity oxygen fuel thermal spray system, Journal of Thermal Spray Technology, 2014, 23, p. 910-918.

[17] J. Browning, Thermal spray method and apparatus for optimizing flame jet temperature, US patent $5330798 \mathrm{~A}$.

[18] J. Kawakita, S. Kuroda, T. Fukushima, H. Katanoda, K. Matsuo, H. Fukanuma. Dense titanium coatings by modified HVOF spraying, Surface \& Coatings Technology, 2006, 201, p. 1250-1255.

[19] S. Kuroda, J. Kawakita, M. Watanabe, H. Katanoda. Warm spraying-A novel coating process based on high-velocity impact of solid particles, Science and Technology of Advanced Materials, 2008, 9, p. 1-17.

[20] H. Katanoda, T. Kiriaki, T. Tachibanaki, J. Kawakita, S. Kuroda, M. Fukuhara. Mathematical modeling and experimental validation of the warm spray (two-stage HVOF) process, Journal of Thermal Spray Technology, 2009, 18, p. 401-410.

[21] H. Katanoda, H. Morita, M. Komatsu, S. Kuroda. Experimental and numerical evaluation of the performance of supersonic two-stage high-velocity oxy-fuel thermal spray (warm spray) gun, Journal of Thermal Science, 2011, 20, p. 88-92.

[22] D. Cheng, Q. Xu, G. Tapaga, E. Lavernia. A numerical study of high-velocity oxygen fuel thermal spraying process. Part I: Gas phase dynamics, Metallurgical and Materials Transactions A, 2001, 32, p. 1609-1620.

[23] M. Li and P.D. Christofides. Modeling and control of high-velocity oxygen-fuel (HVOF) thermal spray: a tutorial review, Journal of Thermal Spray Technology, 2009, 18, p. 753-768.

[24] J. Mostaghimi, S. Chandra, R. Ghafouri-Azar, A. Dolatabadi. Modeling thermal spray coating processes: A powerful tool in design and optimization, Surface \& Coatings Technology, 2003, 163-164, p. 1-11.

[25] E. Dongmo, M. Wenzelburger, R. Gadow. Analysis and optimization of the HVOF process by combined experimental and numerical approaches, Surface \& Coatings Technology, 2008, 202, p. $4470-4478$.

[26] J.S Baik, Y.J Kim. Effect of nozzle shape on the performance of high velocity oxygen-fuel thermal spray system, Surface \& Coatings Technology, 2008, 202, p. 5457-5462.

[27] M. Li, P.D. Christofides. Modeling and analysis of HVOF thermal spray process accounting for powder size distribution, Chemical Engineering Science, 2003, 58, p. 849-857.

[28] M. Li, P.D. Christofides. Multi-scale modeling and analysis of an industrial HVOF thermal spray process, Chemical Engineering Science, 2005, 60, p. 3649-3669. 
[29] M. Li and P.D. Christofides. Feedback control of HVOF thermal spray process accounting for Powder size distribution, Journal of Thermal Spray Technology, 2004, 13, p. 108-120.

[30] M.N. Khan, T. Shamim. Investigation of a dual-stage high velocity oxygen fuel thermal spray system, Applied Energy, 2014, 130, p. 853-862.

[31] M.N. Khan, T. Shamim. Effect of particle and injection parameters on the performance of a dual-stage high-velocity oxygen fuel thermal spray system, Journal of Thermal Spray Technology, 2015, 24, p. 807-816.

[32] V. Yakhot, S. A. Orszag. Renormalization group analysis of turbulence. I. Basic theory, Journal of Scientific Computing, 1986, 1, p. 1-51.

[33] Fluent 6.3, Users Guide, Fluent Inc., 2006.

[34] B.F. Magnussen, B.H. Hjertager. On the mathematical modeling of turbulent combustion with special emphasis on soot formation and combustion, Proceedings of the Combustion Institute, 1976, 16, p. 719-729.

[35] S. Kamnis, S. Gu. 3-D modelling of kerosene-fuelled HVOF thermal spray gun, Chemical Engineering Science, 2006, 61, p. 5427-5439.

[36] S. Kamnis, S. Gu. Numerical modelling of propane combustion in a high velocity oxygenfuel thermal spray gun, Chemical Engineering and Processing, 2006, 45, p. 246-253.

[37] D.B. Spalding. Mixing and chemical reaction in steady confined turbulent flames, Proceedings of the Combustion Institute, 1971, 13, p. 649-657.

[38] T. Poinsot, D. Veynante. Theoretical and Numerical Combustion, $2^{\text {nd }}$ ed., R.T. Edwards Inc., 2005.

[39] B.F. Magnussen. On the structure of turbulent and a generalized eddy dissipation concept for chemical reaction in turbulent flow, $19^{\text {th }}$ American Institute of Aeronautics and Astronautics Aerospace Science Meeting, Missouri, USA, January 12-15, 1981.

[40] J. Chomiak, A. Karlsson. Flame liftoff in diesel sprays, Proceedings of the Combustion Institute, 1996, 26, p. 2557-2564.

[41] S. Gordon, B.J. McBride. Computer program for calculation of complex chemical equilibrium compositions and applications, NASA Reference Publication 1311, Cleveland, USA: Lewis Research Center, 1994.

[42] X. Yang, S. Eidelman. Numerical analysis of a high-velocity oxygen-fuel thermal spray system, Journal of Thermal Spray Technology, 1996, 5, p. 175-184.

[43] D. Cheng, Q. Xu, E. Lavernia, G. Tapaga. The effect of particle size and morphology on the in-flight behavior of particles during high velocity oxy-fuel thermal spraying, Metallurgical and Materials Transactions B, 2001, 32, p. 525-535. 
669 [44] W.E. Ranz, W.R. Marshall. Evaporation from drops (Part I), Chemical Engineering Progress, 6701952,48 , p. 141-180.

671 [45] H.K. Versteeg, W. Malalasekera. An Introduction to Computational Fluid Dynamics, $2^{\text {nd }} e d$, 672 Prentice Hall, Loughborough, 2007.

673 [46] J.D. Anderson. Modern Compressible Flow: with Historical Perspective, $3^{\text {rd }}$ ed., McGraw674 Hill Education, 2002.

675 [47] H. Tabbara, S. Gu. Computational simulation of liquid-fuelled HVOF thermal spraying, 676 Surface \& Coatings Technology, 2009, 204, p. 676-684. 